\title{
Oligonucleotide Therapeutics as a New Class of Drugs for Malignant Brain Tumors: Targeting mRNAs, Regulatory RNAs, Mutations, Combinations, and Beyond
}

\author{
Anna M. Krichevsky ${ }^{1} \cdot$ Erik J. Uhlmann ${ }^{1}$ \\ Published online: 14 January 2019 \\ (C) The Author(s) 2019
}

\begin{abstract}
Malignant brain tumors are rapidly progressive and often fatal owing to resistance to therapies and based on their complex biology, heterogeneity, and isolation from systemic circulation. Glioblastoma is the most common and most aggressive primary brain tumor, has high mortality, and affects both children and adults. Despite significant advances in understanding the pathology, multiple clinical trials employing various treatment strategies have failed. With much expanded knowledge of the GBM genome, epigenome, and transcriptome, the field of neuro-oncology is getting closer to achieve breakthrough-targeted molecular therapies. Current developments of oligonucleotide chemistries for CNS applications make this new class of drugs very attractive for targeting molecular pathways dysregulated in brain tumors and are anticipated to vastly expand the spectrum of currently targetable molecules. In this chapter, we will overview the molecular landscape of malignant gliomas and explore the most prominent molecular targets (mRNAs, miRNAs, lncRNAs, and genomic mutations) that provide opportunities for the development of oligonucleotide therapeutics for this class of neurologic diseases. Because malignant brain tumors focally disrupt the blood-brain barrier, this class of diseases might be also more susceptible to systemic treatments with oligonucleotides than other neurologic disorders and, thus, present an entry point for the oligonucleotide therapeutics to the CNS. Nevertheless, delivery of oligonucleotides remains a crucial part of the treatment strategy. Finally, synthetic gRNAs guiding CRISPR-Cas9 editing technologies have a tremendous potential to further expand the applications of oligonucleotide therapeutics and take them beyond RNA targeting.
\end{abstract}

Keywords brain tumors $\cdot$ microRNA $\cdot$ long noncoding RNA $\cdot$ mutations $\cdot$ epigenetics $\cdot$ gene editing.

Abbreviations
GBM $\quad$ Glioblastoma
WHO World Health Organization
LGG $\quad$ Low-grade glioma
TMZ $\quad$ Temozolomide
OT Oligonucleotide therapeutics
TS Tumor suppressor
Invited Review for the Special Issue on "Nucleic Acid Therapeutics in
Neurological Disease"
Guest editors: Drs. Robert Brown, Anastasia Khvorova, and Jonathan
Watts

Anna M. Krichevsky

akrichevsky@bwh.harvard.edu

1 Ann Romney Center for Neurologic Diseases, Department of Neurology, Brigham and Women's Hospital and Harvard Medical School, Initiative for RNA Medicine, Boston, Massachusetts 02115, USA

$\begin{array}{ll}\text { BBB } & \text { Blood-brain barrier } \\ \text { IDH } & \text { Isocitrate dehydrogenase } \\ \text { 2-HG } & \text { 2-Hydroxyglutarate } \\ \text { CNS } & \text { Central nervous system } \\ \text { CED } & \text { Convection-enhanced delivery } \\ \text { ASO } & \text { Antisense oligonucleotide } \\ \text { SSO } & \text { Splice-switching oligonucleotides } \\ \text { SMA } & \text { Spinal muscular atrophy } \\ \text { ALS } & \text { Amyotrophic lateral sclerosis } \\ \text { HD } & \text { Huntington's disease } \\ \text { AA } & \text { Anaplastic astrocytoma } \\ \text { TME } & \text { Tumor microenvironment } \\ \text { GEM } & \text { Genetically engineered mouse } \\ \text { BNA } & \text { Bridged nucleic acid } \\ \text { UNA } & \text { Unlocked nucleic acid } \\ \text { LNA } & \text { Locked nucleic acid } \\ \text { EV } & \text { Extracellular vesicles } \\ \text { pRNA } & \text { Bacteriophage packaging motor RNA } \\ \text { ncRNA } & \text { Nonprotein-coding RNA }\end{array}$


RBP RNA-binding protein

PFS Progression-free survival

OS Overall survival

\section{Cell and Molecular Landscape of Malignant Gliomas}

\section{Complexity of Malignant Glioma and Therapeutic Challenges}

Glioblastoma (GBM, or astrocytoma WHO grade IV) is diagnosed at a rate of 3 to 4 new cases per 100,000 individuals in the developed countries, corresponding to about 13,000 new cases annually in the USA [1-3]. Despite aggressive treatment with maximum resection followed by concurrent radiotherapy and chemotherapy, the prognosis is still very poor. Merely four drugs and one device received the FDA approval for high-grade gliomas in 30 years, in spite of numerous preclinical and clinical studies. The alkylating agent temozolomide (TMZ) has efficacy both as single agent and with concurrent radiation and is standard-of-care. Median survival of patients receiving standard-of-care treatment remains around 15 months and less than $10 \%$ of the patients survive over 5 years. Therefore, new approaches and therapeutic strategies are critically needed to combat the disease. Extensive multidisciplinary research in neuro-oncology (mostly focusing on GBM) has prospered in the last decade and resulted in about 20,000 peer-reviewed publications. The growing body of knowledge will inevitably lead to therapeutic breakthroughs. The biological and clinical characteristics of GBM have been previously reviewed [1-3]. In the sections below, we will provide a brief introduction to the cell and molecular biology of GBM as a foundation for the development of oligonucleotide therapeutics (OT).

GBM is a highly complex tumor that consists of a tumor core and a surrounding ill-defined invasive zone. At the cellular level, bona fide glioma cells contribute to $\sim 80 \%$ of the tumor mass. The rest comprise of endothelial cells and blood vessels along with the macrophages, microglia, myeloid cells, lymphocytes, and other infiltrating immune cells that are thought to provide immunosuppressive tumor microenvironment (TME) and thereby support tumor growth. Glioma penetrates and actively interacts with the normal brain cells of its microenvironment, including various populations of neurons, astrocytes, and oligodendrocytes. The impact and contribution of glioma microenvironment to tumor growth and progression is a topic of extensive, albeit still young field of research. It is, therefore, becoming increasingly clear that along with the cell autonomous glioma proliferation, growth, and invasion, tumor-promoting activities of other cells of the microenvironment, as well as the communication lines between glioma and
TME cells could be therapeutically targeted. Finally, a special, critical cell population for targeting is glioma stem cells. This rare and thus far only a partly defined type of glioma-initiating cells is considered as the most therapy-resistant, and largely responsible for GBM recurrence.

Although this review focuses on the top signaling pathways and putative molecular targets suitable for OT, it should be noted that tissue and cell-type-specific delivery and productive uptake of oligonucleotides have been thus far achieved for a few cell types only (e.g., hepatocytes) and that efficient targeting of selected cell populations in the brain tumors and CNS will require substantial advances of the field. Whereas drug delivery to the CNS is especially challenging because of the blood-brain barrier (BBB), high-grade gliomas and particularly GBM have partially disrupted BBB. Although this may be expected to facilitate delivery, previous trials have failed to demonstrate such an effect, perhaps owing to a significant delay between tumor cell infiltration and BBB disruption [4]. Therefore, development and optimization of the efficacious oligonucleotide drugs for malignant brain tumors sets a unique set of challenges but also presents opportunities for the field of oligonucleotide therapeutics (OT). In the sections below, we will overview the genetic, epigenetic, and expression landscape of GBM as it suggests the principles for prioritizing the oligonucleotide therapies. Of note, there are numerous genetic, epigenetic, and expression abnormalities found in GBM; we will describe only the most common and characteristic among them that could be potentially leveraged for the oligonucleotide targeting (i.e., "actionable" targets). Based on this information, we will propose the examples of putative OT that could be utilized for the 1) normalization/inhibition of the key overexpressed mRNA, miRNA, and other regulatory RNA species; 2) correction of splicing aberrations; and 3) editing driving mutations in protein-coding genes and regulatory parts of the genome (Fig. 1).

\section{Heterogeneity Defined by Mutations and Expression Patterns}

A major hallmark of GBM and one of the reasons for its therapy resistant nature is the high intratumoral and intertumoral heterogeneity. Several classification systems have been developed to diagnose and stratify the GBM, and ultimately devise rational anti-GBM therapies. The Cancer Genome Atlas (TCGA), established for GBM more than 10 years ago, and for low-grade gliomas (LGG) more recently, integrated multidimensional genomic and expression datasets and, thus, largely contributed to current understanding of glioma etiology and heterogeneity [5, 6]. Adult GBM may arise de novo and present as primary GBM, or alternatively progress 


\section{mRNA/IncRNA up-regulated} (Oncogene)

SiRNA

ASO

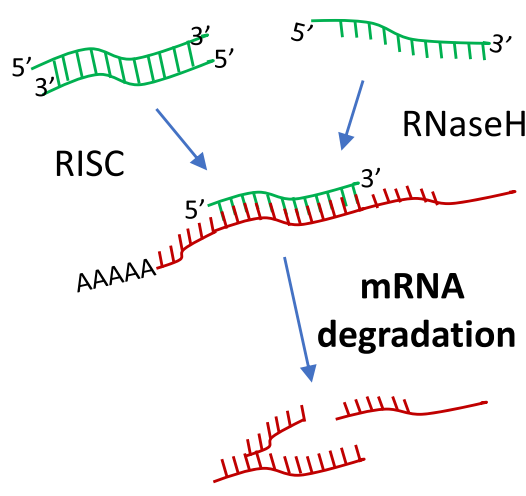

mRNA mis-spliced

Splice-switching oligo



Splicing correction

microRNA

up-regulated

\section{Anti-miRs}

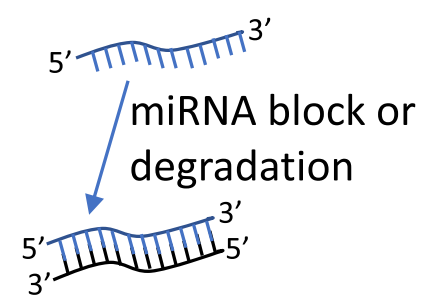

miRNA inhibition

mRNA target de-repression
mRNA/ncRNA down-regulated

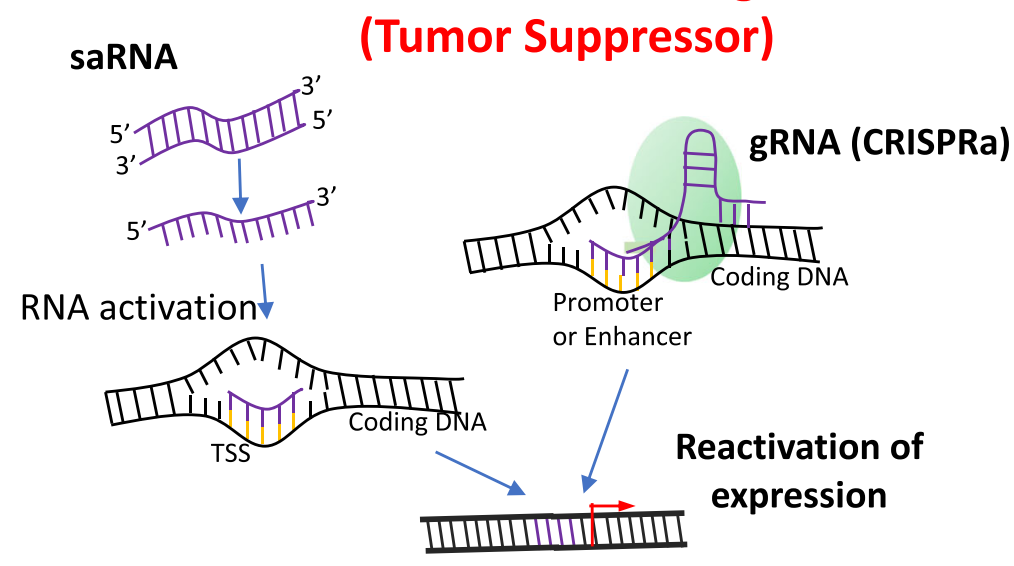

Gene editing of oncogenes or regulatory elements

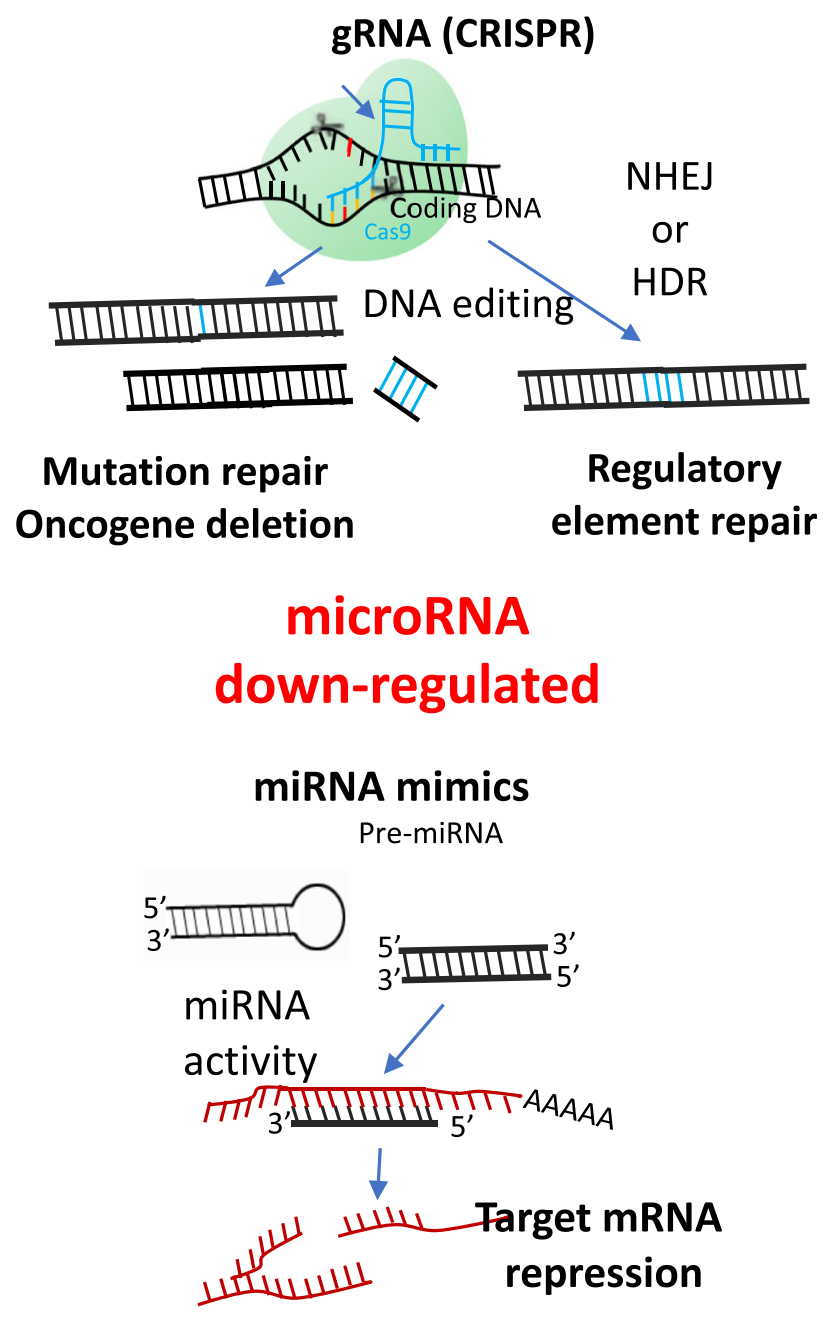

Fig. 1 Oligonucleotide therapeutics for GBM 
from lower-grade IDH-mutant glioma to so-called secondary GBM [7]. Morphologically, primary and secondary GBMs are largely undistinguishable; however, their genetics, molecular biology, clinical presentation, and prognosis are highly distinct. The majority of GBM cases (>92\%) manifest at advanced age (mean, 62 years) as the primary disease and are characterized by widespread anatomic distribution. Secondary GBM usually develops in younger patients (mean, 45 years); involves the frontal lobe, in particular the region surrounding the rostral extension of the lateral ventricles; and has significantly longer overall survival than primary GBM [8]. The major genetic marker of primary versus secondary GBM is the status of IDH1, the gene encoding isocitrate dehydrogenase 1 , which is almost uniformly WT in primary GBM while mutated in secondary disease [8]. IDH1 mutations are also frequent $(>80 \%)$ in diffuse gliomas and a subset of anaplastic astrocytomas (WHO grades II and III, correspondingly), the precursor lesions of secondary GBM, as well as in oligodendroglial tumors of WHO grades II and III [9-11]. Although rare, IDH2 mutations are also observed in anaplastic oligodendrogliomas and oligoastrocytomas [12]. Therefore, IDH1/2 mutations could be considered as an early event in gliomagenesis, and they are preserved during progression to higher-grade disease.

The oncogenic effect of IDH mutations is thought to be at least twofold. The IDH enzymes catalyze the oxidative decarboxylation of isocitrate to $\alpha$-ketoglutarate ( $\alpha-\mathrm{KG})$. IDH1/2 mutations are gain-of-function mutations that divert the enzyme to produce the oncometabolite 2-HG. Moreover, the catalytic rate is greatly increased, up to 100 -fold, resulting in very high concentrations of 2-HG. Because of structural similarity, 2-HG inhibits enzymes that normally bind $\alpha-\mathrm{KG}$ (either at the active site or an allosteric regulatory site), including $\mathrm{HIF}-1 \alpha$ resulting in upregulation of VEGF [13], as well as histone demethylases (e.g., prolyl hydroxylases, collagen prolyl-4-hydroxylase, and the ten-eleven translocation (TET) family of DNA hydroxylases [14], which in turn results in aberrant histone methylation. Changes in histone methylation impair cell differentiation and thus predispose to malignant transformation [15]. Finally, IDH1/2 ${ }^{\text {mut }}$ display concerted $\mathrm{CpG}$ island hypermethylation at a large number of loci $(\mathrm{G}-$ CIMP phenotype), and this phenotype is associated with extended GBM survival. Conversely, the absence of $I D H$ mutations and G-CIMP-low phenotype in LGG mark a distinct subgroup characterized by poor, GBM-like prognosis [6, 16]. Altogether, $I D H 1 / 2^{m u t} /$ secondary GBMs comprise a small and fairly homogeneous subclass of GBMs, whereas primary GBMs are more diverse.

The integrated analysis of TCGA further refined the GBM classification based on genetic and expression signatures reminiscent of different neural lineages. The initial analysis identified mesenchymal, classical, proneural, and neural expression patterns [17]. This classification has been recently revised to include only three major classes of classical, mesenchymal, and proneural gliomas that are broadly characterized by alterations in EGFR, NF1, and PDGFRA pathways, respectively. The neural GBM group was removed from this classification as likely reflecting the contamination by the normal neural cells [18]. Classical GBM is marked by the high-level EGFR amplification and a corresponding four-fold increase in EGFR expression, along with a significant proportion of the vIII EGFR mutation. In addition, neural precursor and stem cell marker NES, as well as Notch (NOTCH3, JAG1, and LFNG) and Sonic hedgehog (SMO, GAS1, and GLI2) signaling pathways, is highly expressed in this subtype [17]. Mesenchymal GBM is characterized by deletions, mutations, and the correspondingly reduced expression of NF1, coinciding in some cases with PTEN mutations. These events mark the activation of the Ras pathway and intersect with the Akt survival axis. The combination of higher activity of mesenchymal markers (CHI3L1 and MET) along with CD44 and MERTK is reminiscent of an epithelial-to-mesenchymal transition that has been linked to dedifferentiated and transdifferentiated tumors [19]. Genes in the tumor necrosis factor super family pathway and NF- $\mathrm{KB}$ pathway, such as TRADD, RELB, and TNFRSF1A, are highly expressed in this subtype, potentially as a consequence of higher overall necrosis and associated inflammatory infiltrates in the mesenchymal class. The proneural GBM is featured by either IDH1 mutations or alteration of PDGFRA, including amplifications and mutations, and overall has a better prognosis. Proneural tumors with no PDGFRA aberrations are often mutated in PIK3CA/PIK3R1. Other genetic alterations that significantly impact gene expression, such as CDKN2A deletions and TP53 mutations, are more common to two or all three GBM subgroups. Overall, despite high genetic and expression heterogeneity of GBM, the TCGA analysis indicates that three major signaling pathways associated with cell cycle, senescence, and apoptosis are commonly dysregulated: RTKs/Ras/PI3K (in 88\% of GBM), MDM/P53/CDKN1A/ CDKN2A/apoptosis (87\%), and CDKN2A/CDKs/RB1 $(78 \%)[6,16]$. We will focus on the central targets for the OT, involved in these signaling pathways, in the section "mRNA Normalization by OT: Expanding the Repertoire of Targetable Molecules to Transcription Factors, RNA-Binding Proteins, and Other Protein Factors."

In addition to the alterations in protein-coding sequences, several mutations in regulatory regions of the genome are strongly associated with GBM and might provide targets for the OT-guided function-restoration therapy. The most prominent among them are mutations in the telomerase reverse transcriptase promoter (TERTp) that have been reported in 80 to $90 \%$ of GBM $[20,21]$, at much higher rate than in other cancers. Normal brain tissues, with the exception of neural stem cells, do not express telomerase; however, in GBM, TERTp mutations (TPMs) lead to upregulation of TERT 
mRNA expression through the creation of a de novo transcription factor-binding site [22]. Generally, reactivation of telomerase activity is considered as a single most consistent feature of cancer. Essential for neoplastic growth, telomere lengthening and maintenance is required to escape replicative senescence. Telomerase may thus represent the most effective cancer therapeutic target [23]. Indeed, imetelstat, a competitive telomerase inhibitor, demonstrated promise in preclinical GBM models [24] and in the phase II study of pediatric brain tumors [25]. Curiously, the TCGA analysis indicates that TPMs correlate with generally reduced, rather than increased telomere length in GBM [20]. In contrast, mutations in the telomere-binding protein alpha thalassemia/mental retardation syndrome X-linked ATRX, which are nearly exclusive with the TERTp mutations, correlated with increased telomerase length and may thus underlie a telomere maintenance mechanism in GBM [26]. Although there are alternative mechanisms of TERT function proposed [23], and the whole spectrum of downstream consequences of TPM and TERT activation remains to be further investigated, correcting these hallmarks of the GBM with OT could represent a viable and robust approach.

\section{Epigenetic Alterations: DNA and Histone Modifications and 3D Organization}

Extensive epigenetic remodeling that includes global DNA hypomethylation and chromatin remodeling takes place during gliomagenesis (reviewed in Gusyatiner and Hegi [27]). In addition to the critical function of IDH1/2 mutations in the DNA methylation patterns and epigenetic regulation described above, several epigenetic mechanisms have been implicated in gliomagenesis. The epigenetic silencing of the DNA repair gene MGMT by promoter methylation (pMGMTmet) in approximately half of GBM tumors is highly predictive for positive response to TMZ. The MGMT gene encodes the DNA repair enzyme O6-methylguanine-DNA methyltransferase that restores O6-methylguanine, the main adduct generated by TMZ, thereby blunting the effect of chemotherapy. Methylation status of pMGMT is often associated with the G-CIMP phenotype and currently used as a primary biomarker for risk stratification in gliomas (WHO 2016). Several studies validated a significant concordance between unmethylated pMGMT and MGMT protein expression and association of this status with reduced survival [28, 29]. These data suggest that lowering MGMT levels in patients with unmethylated pMGMT/high MGMT may sensitize them to TMZ therapy.

On a broader scale, TCGA-based studies continue to identify new alterations in the genes involved in chromatin organization. Although this topic has been thoroughly reviewed recently [27], several findings deserve attention as directly related to major epigenetic aberrations that are potentially targetable by OT. Generally, histone marks define the chromatin structure and, thus, the transcriptional activation status of a gene. These marks are established and regulated by numerous epigenetic modifiers, writers, readers, and erasers. The most common marks associated with active genes are trimethylation of lysine 4 ( $\mathrm{H} 3 \mathrm{~K} 4 \mathrm{me} 3)$ and acetylation of lysines 9 and 27 (H3K9ac and $\mathrm{H} 3 \mathrm{~K} 27 \mathrm{ac})$, whereas inactive genes are usually marked with $\mathrm{H} 3 \mathrm{~K} 9 \mathrm{me} 3$ and $\mathrm{H} 3 \mathrm{~K} 27 \mathrm{me} 3$. Notably, in pluripotent and multipotent cells such as embryonic stem (ES) and neuroprogenitor cells (NPCs), critical regulatory genes may display both $\mathrm{H} 3 \mathrm{~K} 4$ and $\mathrm{H} 3 \mathrm{~K} 27$ trimethylation, a chromatin signature referred to as 'bivalent domains' that are poised for rapid activation or, diversely, silencing. Such events may shift a balance in expression of oncogenes and tumor suppressors, and lead to malignant transformation and tumorigenesis [30]. A major factor in this regulation $\mathrm{PRC} 2$ has histone methyltransferase activity and silences gene expression by dimethylating or trimethylating H3K27. One of its enzymatic subunits, enhancer of zeste homolog 2 (EZH2) has been reported as oncogenic in high-grade glioma (HGG) [31-33]. Histone acetylation is balanced by activities of histone acetyltransferases (HATs) and deacetylases (HDACs).

At least one of a set of 36 genes involved in chromatin and histone modifications is frequently altered in gliomas, most of which belonged to the IDH1/2 mutant-non-1p/19q-codeleted group [20]. Predicted glioma drivers associated with chromatin organization include ATRX, SETD2, ARID2, DNMT3A, SMARCA4, and ARID1A. ATRX, the most commonly mutated among them (in 37\% of diffuse gliomas), forms a complex with DAXX and histone 3 variant H3.3, the genes frequently mutated in pediatric gliomas [34]. The ATRXDAXX-H3.3 complex is associated with the alternative lengthening of telomeres. Also, the genes for histones themselves are frequently mutated in pediatric gliomas (will be discussed below). Interestingly, pediatric and adult GBM converge on dysregulation of H3.3 through mutations in the former and epigenetic repression via histone-lysine methyltransferase mixed lineage leukemia 5 (MLL5) in the latter. In adult GBM, MLL (which is upregulated in some cases) alters global chromatin conformation and suppresses differentiation of GBM stem cells [35].

Besides DNA methylation and histone modifications, 3D architecture of the chromatin emerges as an additional highorder regulatory layer controlling gene expression. This structural organization is largely mediated by the CCCTC-binding factor (CTCF) and cohesin complex that participate in the formation of highly conserved topologically associating domains (TADs). The majority of known promoter-enhancer interactions do not cross TAD boundaries. Disruption of such boundaries can promote differential gene expression in gliomas via creation of new promoter-enhancer pairs [36]. CTCF, whose activities are required in early development to regulate 
the balance between proliferation, differentiation, and survival of cortical progenitor cells [37], has been also directly implicated in gliomagenesis [36]. Specifically, IDH1 mutant gliomas exhibit hypermethylation at cohesin and CTCF-binding sites, thereby inhibiting the CTCF binding that is crucial for proper organization of TADs. Loss of the CTCF binding was shown to activate the enhancer of PDGFRA, a prominent glioma oncogene [36]. The full impact of CTCF and other TAD organizers on the dysregulated gene expression in gliomas remains to be investigated. Of note, a subset of gliomas showed mutations or copy number alterations in multiple genes involved in the cohesin complex, including the gene STAG2 [20, 38]. Remarkably, a recent CRISPR-based screen demonstrated that mutations in CTCF and histone modifiers EP300 (HAT) and MLLs are among the most frequent events driving the astrocyte transformation to GBM in mice in vivo [39]. Altogether, this data suggests that targeting epigenetic modifiers and regulators of chromosomal topology may provide a feasible therapeutic approach for the GBM.

Of note, several drugs directed against epigenetic pathways (e.g., HDACs, mutant IDH1, EZH2, and DNMT) have been clinically tested for different malignancies, including glioma $[27,40,41]$. These strategies, in essence, aim to reverse dysregulated gene expression. However, because of the fundamental roles of the targets in both tumor and normal cells, they may lead to global effects on the genome and thus cause further dysregulation rather than normalization of expression. For example, inhibitors of DNA methylation showed preclinical efficacy in vitro and in vivo in IDH mutant glioma, and novel second-generation hypomethylating drug guadecitabine with improved pharmacodynamic characteristics is currently tested in a phase III study in AML. However, it remains controversial whether broad-spectrum demethylation is desired in glioma, as unwanted proto-oncogenes may be activated. Demethylation of the MGMT promoter may increase temozolomide resistance. Specific OT-based gene-targeted strategies, coupled with selective cell uptake and precise dosing regimens, could provide improved selectivity and specificity of targeting cancer cells.

\section{Pediatric Glioma}

Although the most common glioma in adults is GBM, in children, low-grade gliomas and embryonal tumors, such as cerebellar pilocytic astrocytoma, pediatric diffuse astrocytoma, pleomorphic xanthoastrocytomas, and medulloblastoma, are the most prevalent. Although pediatric HGG is relatively rare, the prognosis is poor even with best available therapy. Histone mutations are very characteristic, such as the K27M mutation of the histone H3.1 or H3.3 isoform and G34R or G34V mutations of H3.3. The H3K27M mutation effectively turns on gene expression by not allowing trimethylation of the $\mathrm{H} 3$ Lysine 27 residue for transcriptional silencing [42].
Although the H3K27M mutation does not provide a direct therapeutic target, downstream effectors such as specific transcription factors (TFs) may be identified as suitable targets. Pediatric high-grade gliomas also commonly harbor IDH1 $\mathrm{R} 132 \mathrm{H}$ and BRAF V600E mutations, as well as CDKN2A, NF1, TP53, PDGFRA, PIK3CA, PIK3R1, and FGFR1 alterations and NTRK fusions [43, 44], providing further potential therapeutic targets.

Ultimately, mutations and epigenetic alterations that accumulate during gliomagenesis lead to a profoundly dysregulated gene expression, which manifests at the levels of mRNAs/ proteins, microRNAs, and other regulatory RNAs. Prior to discussing candidate RNA targets for the OT, we provide a brief overview of the oligonucleotides as the CNS therapeutics with the focus on drugs tested in human clinical trials for GBM.

\section{Development of Oligonucleotide Therapeutics for Brain Tumors}

\section{Clinical Experience and Considerations}

Oligonucleotides are short, DNA- or RNA-based synthetic polymers (usually 13-30 nucleotide long) that are considered as a gene-modulatory class of drugs, along with small molecules and antibodies. Oligonucleotides bind to RNA (and in some cases to DNA) through Watson-Crick base pairing and, upon binding, modulate functions of the targeted nucleic acids in a sequence-specific fashion. Therefore, OT can be developed to target both protein-coding and regulatory nonproteincoding RNA (ncRNA), as well as protein-coding and regulatory DNA sequences of the genome with high specificity. Traditionally, the major classes of oligonucleotides developed for therapeutics were single-stranded ASOs that promote mRNA target degradation by engaging RNase $\mathrm{H}$ cleavage or modulate mRNA splicing via steric block of specific splice sites and exon skipping. Overall, in the past 5 years, over 100 antisense OTs have been tested in phase I clinical trials, a quarter of which have reached phase II/III. More recently, the field expanded with siRNAs and miRNA-modulatory oligonucleotides (both antagonists and mimics) and is currently further spurred with the emergence of oligonucleotide-guided gene-editing technologies such as CRISPR/Cas9 (Fig. 1).

Unmodified DNA and RNA oligonucleotides are inherently unstable; to become useful as drugs, they must be chemically modified to increase their nuclease resistance, but also retain or enhance tissue distribution, cell uptake, and target recognition [45-47]. The predominant cell uptake mechanism for oligonucleotides is endocytosis, and the majority of internalized oligonucleotides are trapped in the endocytic compartment leading to poor target recognition and low functional activity. Systemic administration results in rapid and broad 
tissue distribution within just a few hours, with the highest concentrations accumulating in the liver and kidney. Both size and charge of most oligonucleotides prevent their distribution across the intact BBB. Nevertheless, modified oligonucleotides administered by intrathecal injection distribute broadly in the CNS. Recent advancements that enable OT delivery to the brain and malignant gliomas via local (intratumoral, intrathecal, convection-enhanced delivery (CED)) and systemic (intravenous, intranasal) routes are reviewed in the section "Oligonucleotide Delivery to Malignant Glioma: Selective Targeting with Aptamers, Cell-Penetrating Peptides, and Nanoparticles."

The fairly limited clinical attempts to investigate oligonucleotide drugs for various neurologic diseases have been previously reviewed [45-47]. Importantly, the OT approach was approved by FDA for spinal muscular atrophy (SMA), a single-gene inherited neurological condition, and clinical trials on amyotrophic lateral sclerosis (ALS) and Huntington's disease (HD) are ongoing [48, 49]. However, brain tumors such as GBM might present considerable additional challenges. For the treatment of SMA, caused by homozygous deletion of the SMN1 gene, intrathecal administration of a modified ASO nusinersen increases the amount of the SMN protein in alpha motor neurons by altering the distribution of alternatively spliced transcripts from the SMN2 gene [50]. In this case, relatively low levels of the SMN protein (10-20\% of wild type) may be sufficient for the normal functioning of alpha motor neurons. Furthermore, even a subset of motor neurons that can be preserved or restored to normal function can sustain mobility and respiration. Accordingly, nusinersen was shown to produce clinically significant improvements in treated infants [51, 52]. However, the required modulatory effects of oligonucleotides employed in GBM treatment are likely to be substantially higher, because virtually all tumor cells need to be reached and eliminated, in order to have a therapeutic effect. Small molecule drugs, such as receptor tyrosine kinase inhibitors (RTKi) tested thus far, showed no benefit for GBM, although effective in other malignancies such as lung or kidney cancer. Oligonucleotides are typically much larger than small molecule drugs $(393.4 \mathrm{~g} / \mathrm{mol}$ for the EGFR inhibitor erlotinib and $7127.2 \mathrm{~g} / \mathrm{mol}$ for nusinersen); this not only makes administering equivalent molar quantities of the OT more difficult but also reduces BBB penetrance and tissue distribution of the drug. Thus, OTs will only be effective if these pitfalls are circumvented, as outlined in the sections below.

Four reported human clinical trials tested OTs for GBM thus far. The first phase II trial, concluded in 2005 [53], used aprinocarsen, a phosphorothioate ASO to the 3 '-untranslated region of human PKC- $\alpha$ mRNA, that inhibited PKC- $\alpha$ expression through RNase H-mediated cleavage of the mRNA [54]. This trial was based on the early work from 1987 to 1999 that suggested the benefits of PKC- $\alpha$ inhibition in several animal models of cancer, but included only minimal preclinical data relevant to glioma and limited to U87 model only [55]. Aprinocarsen was administered at $2 \mathrm{mg} / \mathrm{kg} / \mathrm{day}$ to patients with $\mathrm{HGG}$ as a continuous intravenous infusion in $21 /$ 28 -day cycles. Neither neurologic toxicity nor tumor responses or clinical benefits were observed. The effect of PKC- $\alpha$ inhibition on the BBB integrity was suspected, and no follow-up studies were reported.

Another set of trials tested a transforming growth factor- $\beta 2$ inhibitor trabedersen, a phosphorothioate ASO, in recurrent high-grade gliomas [56-58]. TGF- $\beta$ is a potent cytokine with multiple biological activities which became attractive for GBM targeting because of its role in glioma proliferation, migration, invasion, angiogenesis, and immunosuppressive properties [59]. The safety and efficacy of trabedersen have been established through pharmacokinetic and toxicology studies in vitro and in rabbits and primates in vivo [60]. In phase I/II dose escalation studies on adult HGG patients, the maximum tolerated dose was not reached [57], indicating a favorable safety profile of the oligonucleotide. A follow-up randomized and controlled phase IIb study of 145 patients with recurrent or refractory AA and GBM further evaluated the efficacy and safety of 2 doses $(10$ and $80 \mu \mathrm{M})$ administered intratumorally by CED. A benefit of $10 \mu \mathrm{M}$ trabedersen versus standard chemotherapy for the 14-month tumor control rate and a trend for its superiority for 2-year survival rate of AA (but not GBM) patients was reported [56]. However, the study was criticized for suboptimal design and insufficient statistical power [61, 62]. Additional multinational phase III study designed to test the efficacy and safety of $10 \mu \mathrm{M}$ trabedersen was discontinued in 2014 because of slow recruitment. Despite the disappointing lack of conclusions of these trials, they validated the safety of the locally administered phosphorothioate oligonucleotides for glioma patients. More recent preclinical data further reinforced TGF- $\beta$ as a relevant target in GBM growth and radioresistance $[63,64]$.

A set of clinical trials utilized the immunostimulating oligodeoxynucleotides containing unmethylated cytosineguanosine motifs (CpG-ODN). Phase I and II trials with the CpG-ODN infused into surgical cavity after GBM removal concluded that, although well tolerated at doses up to $20 \mathrm{mg}$, the drug did not improve survival $[65,66]$. Notably, these past trials utilized early generation of OTs and have examined neither drug delivery and distribution in the brain tumor tissues nor target engagement or specific biomarker response. Therefore, the lack of efficacy can be attributed to poor delivery, lack of activity, or suboptimal selection of the molecular target.

Imetelstat (GRN163L, Geron Corporation, Menlo Park, CA), a covalently lipidated 13-mer-thiophosphoramidate oligonucleotide that binds to the template region of the RNA component of telomerase, and thus serves as competitive telomerase inhibitor, demonstrated promise in preclinical GBM models [24] and was tested in the phase II study of recurrent 
pediatric brain tumors [25]. The drug was administered as intravenous 2-h infusion at $285 \mathrm{mg} / \mathrm{m}^{2}$ to patients with $\mathrm{HGG}$, DIPG, medulloblastoma, and ependymoma. Although the regimen proved too toxic in children and the trial was terminated, it was concluded that the drug crossed the BBB and achieved both intratumoral and PBMC target inhibition [25].

This summary indicates a critical need in a thorough strategy for the identification of the most promising molecular targets for OT for HGG, development of the specific glioma-targeting OT, and carefully designed preclinical and clinical studies to test their distribution, efficacy, safety, and target engagement in HGG. Potential strategies for OT administration to HGG are illustrated in Fig. 2.

\section{Characteristics and Limitations of Current Preclinical Cell and Animal Models}

Preclinical studies of candidate therapeutics for malignant gliomas have long suffered from poor animal models and often relied on cultured glioma cell lines only (reviewed in McNeill et al. [67]). For decades, glioma drug discovery has been largely carried out on a few cell lines, with U87 being the most commonly used among them for practical rather than biological reasons. These lines, grown in fetal serum, exhibit molecular characteristics that are vastly different from primary glioma cells, weakly tumorigenic, noninvasive, and scantly vascularized in nude mice, and thus not reliably modeling human GBM. In contrary to human HGG, these orthotopic models also have largely intact BBB, further limiting their relevance for glioma drug discovery programs. Newer models based on xenografts derived from low-passage glioma-initiating cells (GSCs) cultured in defined serum-free conditions or passaged in mice in vivo more faithfully recapitulate the infiltrating character of human GBM and are more suitable for drug discovery and optimization studies, including these on OTs. However, such models exhibit higher interexperimental variability and are, thus, more labor-intensive and costly. It should be also noted that subcutaneous models of glioma lack the natural brain microenvironment comprised of multiple nonglioma cell types contributing to the intratumoral communication and tumor growth [68], and thus represent an inadequate surrogate of the disease. In addition to glioma xenografts and allografts, genetically engineered mouse models (GEMs) bearing characteristic mutations and specific alterations in signaling pathways have been developed and provide a benefit of the immunocompetent brain TME [67]. Altogether, with increased recognition of the molecular heterogeneity of HGG ecosystems, employment of multiple complementary in vitro and in vivo models should become a standard requirement for glioma drug development, to ultimately increase the success of clinical trials.

\section{Oligonucleotide Delivery to Malignant Glioma: Selective Targeting with Aptamers, Cell-Penetrating Peptides, and Nanoparticles}

Recent work suggests that chemically stabilized oligonucleotides can be delivered to orthotopic infiltrating GBM in mice via various delivery routes (intratumoral injections, CED infusions, and systemic intravenous and subcutaneous injections), both unformulated and formulated in LNPs, and lead to functional inhibition of a target and significant effects on tumor growth [69-71]. However, further improvements in chemistry are needed to increase the oligonucleotide stability and half-life, glioma-selective uptake, endosomal escape, potency, and target specificity. It should be also noted that in mice, BBB penetrance, delivery, and distribution of a given oligonucleotide in the tumor tissues, and thus its overall efficacy, depend largely on a GBM model, its cellular properties, invasiveness, and vascularization.

The OTs composed of only of DNA or RNA bases are rapidly degraded in a biological system by endo- and exonucleases and phosphatases. The efforts of the field are focused on the development of 1) sugar, backbone, and end
Fig. 2 Strategies for OT administration to malignant glioma

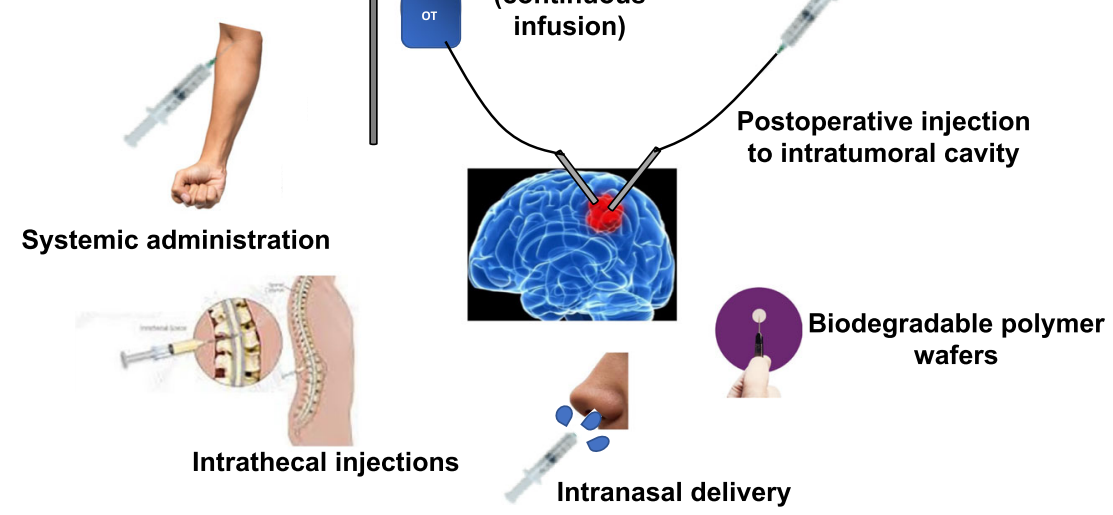


modifications improving OT nuclease resistance and stability; 2) tail modifications enhancing tissue uptake and distribution; 3) chemical conjugations to various targeting moieties (e.g., aptamers, cell-penetrating peptides, and antibodies); and 4) formulations with lipid, magnetic, and other nanocarriers to further enhance the selective targeting and internalization of the oligonucleotides (reviewed by Geary et al. [47], Khvorova and Watts [72], and Lima et al. [73]). The contemporary, clinically advanced OTs are partly or fully stabilized molecules with modified backbones, with natural phosphodiester bonds replaced by phosphorothioate (PS), phosphodithionate (PS2), phosphonoacetate (PACE), phosphorodiamidate morpholino oligomers (PMO), or peptide nucleic acid (PNA). Most commonly used sugar modifications include 2'-OMe, 2'-O-MOE, LNA, 2'-F, ethylene-bridged nucleic acid (ENA), BNA, and UNA. Combinations of various sugar modifications with the PS backbone are commonly utilized. The comprehensive overviews of the oligonucleotide evolution history have been recently published $[72,74,75]$; here we will focus on the progress in advancing the oligonucleotide designed to target malignant gliomas.

Several approaches based on the receptor-mediated uptake have been developed to enhance the efficiency and selectivity of oligonucleotide targeting to glioma cells and tumors. One of them utilizes aptamers, or "chemical antibodies," short single-stranded nucleic acids (RNA or ssDNA) selected from a partially random oligonucleotide library via the in vitro procedure denominated systematic evolution of ligands by exponential enrichment (SELEX) [76]. Molecules bound with high affinity and specificity to a cell surface, complex macromolecular structures, or receptor of interest can be identified in multiple rounds of positive and negative selection and further optimized. Similar to antibodies, aptamers have a broad range of applications such as therapeutics and imaging agents. The first aptamer to reach phase II clinical trials for several cancers, AS1411, is a nucleolin-specific oligonucleotide. Nucleolin is a ubiquitously expressed cell surface marker for various cancer cells; therefore, although initially developed for nonglioma cells [77], AS1411 also binds to glioma. AS1411 appears to inhibit the proliferation of glioma cells but not normal astrocytes in vitro and prolong the survival of subcutaneous U87 glioma-bearing mice [78]. Nanoconjugates of chemotherapeutics such as paclitaxel with AS1411 showed enhanced glioma cytotoxicity compared with paclitaxel without aptamer [79]. Additional studies identified the aptamers that bind to glioma EGFRvIII, PDGFRb, EphB2/3, and tenascin-C receptors and examined their conjugation with several siRNAs, miRNAs, and anti-miRNAs (reviewed by Delac et al. [76] and Amero et al. [80]). For example, the PDGFR $\beta$ targeted aptamer chimera bearing the siRNA to STAT3 reduced glioma cell viability, tumor growth, and angiogenesis in a subcutaneous model of glioma [81]. The major flaw of many prior SELEX screens, however, is that they utilized one or few glioma cell lines only (most often U87), and thus, the selected aptamers may not be efficacious for heterogeneous glioma cells and tumors. More systematic approaches for the identification of ligands and aptamers targeting a variety of tumor cells, including tumor-initiating stem cells in multiple heterogeneous tumors, still have to be developed [82]. Although the utility of aptamer conjugates with siRNA and other OT for orthotopic GBM remains to be explored, recent pilot findings denoting that aptamers may cross the BBB and accumulate in the GBM $[83,84]$ and suggest their potential as a new type of therapeutic vehicles.

An alternative approach to improve the internalization of OT is through the small nontoxic cell-penetrating peptides (CPP) that utilize endocytosis and direct translocation but may also internalize via the receptor-mediated uptake (e.g., via EGFR [85]) and thus provide selectivity for tumor cells such as GBM. Although the CPPs appear fairly efficient as transfection reagents to glioma cells in vitro [86, 87], only limited in vivo data have been reported thus far. In one study, conjugation of the stathmin-targeted siRNAs to a PP75 CPP appeared to improve the effect of siRNA when the complex was injected to subcutaneous U251 glioma xenografts [88]. A rationally designed amphipathic $\alpha$-helical peptide NF55 produced stable nanoparticles with nucleic acids, promoted endosomal escape, and demonstrated efficacy in several animal models, including an orthotopic GBM model [89]. A recent report described the first example of an antibodyantisense strategy directed to GSCs. The GSC-targeting CD44 antibody was conjugated with a stabilized ASO targeting the gene downregulated in renal cell carcinoma (DRR), a genetic driver of GSC invasion [90], and mediated the internalization of the ASO and DRR knockdown [91]. Additional conjugates of the oligonucleotides, for example with neuroactive lipids such as cholesterol, have also been shown to significantly improve their distribution and uptake in the orthotopic GBM [69].

The BBB presents the major challenge for systemic drug administration to all neurologic diseases. However, in malignant brain tumors, the BBB is partially disrupted and leaky, potentially enabling a facilitated route for a drug to the tumor, compared to the brain parenchyma. Nevertheless, the degree of the BBB penetrance varies among the tumors and may diminish when a successful therapy reduces the tumor burden, making the subsequent treatments of the residual tumor less efficacious. Approaches to further improve drug delivery through the BBB and monitor the quantitative uptake at different stages of tumor growth and recurrence are, thus, warranted. Recent clinical trials suggested that repeated opening of the BBB with a pulsed ultrasound, in combination with systemic microbubble injections, is well tolerated in GBM patients and has the potential to facilitate chemotherapy [92] and delivery of other drugs such as OTs [93]. Limited work has been carried out to investigate and improve the BBB 
penetrance of the OT for brain tumors thus far. Several CNStargeting ligands such as Rabies virus glycoprotein (RVG) peptide [94, 95], apolipoprotein E [96-98], Angiopep-2 [99], and transferrin [100] were proposed to improve drug delivery to the brain parenchyma through the BBB and may provide a starting point for the development of the ligand/ receptor-mediated targeting to HGG too. Further work in the field should capitalize on these discoveries.

Several formulations of OTs in nanoparticles (NPs), including lipid and metal (e.g., gold or iron) NPs, have been investigated in preclinical glioma studies. NPs may provide carriers that would increase the stability and reduce renal clearance of the OT and other systemically administered drugs (reviewed in Lozada-Delgado et al. [101]). They can be decorated with ligands such as a glioma-specific peptide chlorotoxin [102] to potentiate the selective targeting. Only a few of the preclinical studies led thus far to human clinical trials on GBM, such as the ongoing phase II trial of the cationic liposomes encapsulating the cDNA for wild-type p53 [103]. The first human safety trial administering intravenously a siRNA utilizes spherical nucleic acid nanoparticles (SNAs) and is currently recruiting GBM patients [104]. The SNAs consist of gold nanoparticles (13 nm AuNPs) covalently bound with densely packed, highly oriented siRNA duplexes to oncoprotein Bcl2L12 [105]. The particles can cross the BBB through targeting class A scavenger receptors [106], and they are anticipated to reduce the Bcl2L12 expression and thus sensitize glioma toward therapy-induced apoptosis by enhancing effector caspase and p53 activity.

Finally, the natural nanoparticles - cell-derived extracellular vesicles (EVs) or exosomes - have recently attracted researchers as potential vehicles for the OT delivery to various cells and tissues. As EVs contain endogenous small nucleic acids, efficiently internalized by various recipient cells $[68$, 107] and can be loaded with synthetic oligonucleotides [108], they may provide an alternative targeting strategy. The efficacy and safety of this new delivery approach, along with the optimal cell sources for the production of EV therapeutics, remain to be investigated.

Box 1. Major advantages of the oligonucleotide therapies

- Once the biological and chemical principles defining the ON delivery, distribution, and efficacy in the brain and brain tumors and overall low toxicity are established, they are expected to be adaptable for multiple targets in combination therapies. Relative to antibody and small molecules, OT drug development is faster, cheaper and does not involve large-scale target screens, design, and production efforts.

- OT technology substantially expands the repertoire of targetable molecules, as the protein factors previously considered nontargetable (e.g., TFs and RBPs) can be modulated at the level of $m R N A$ transcripts, along with regulatory RNA such as miRNAs and IncRNAs.

- Potential applications of OT include transcription activation by small activating RNA and oligonucleotide-guided genome editing.

Overall, OT may offer potential advantages of high specificity and selectivity, low toxicity, and possibility of combination therapies.

\section{mRNA Normalization by OT: Expanding the Repertoire of Targetable Molecules to Transcription Factors, RNA-Binding Proteins, and Other Protein Factors}

Initially, OTs have been proposed for the modulation of mRNA levels and splicing. Apparent mRNA targets for the GBM combination therapies can be devised from previous attempts to utilize small molecule drugs targeting the RTKs, which have been successful in other cancers but failed as monotherapies in GBM. Gefitinib, erlotinib, afatinib, and osimertinib are first-line treatment choices for patients with locally advanced or metastatic non-small cell lung cancer harboring epidermal growth factor receptor tyrosine kinase mutations [109]. Sunitinib, pazopanib, and temsirolimus are among the first-line treatment options for metastatic renal cell carcinoma [110]. The reasons for RTKi trial failures in GBM are thought to be diverse and include poor penetration of the drug into the tumor tissue, lack of reliance of the GBM cells on one particular signaling pathway, and rapid and effective metabolism of the drug by tumor cells [4]. For example, EGFR blockage may be circumvented by GBM cells by PDGFRA, ERBB2, or MET pathways [5]. Upstream activation of the EGFR pathway by NFKBIA deletion is common in GBM [111].

\section{OT Is Uniquely Selective Allowing TF Targeting}

Oligonucleotides may offer distinct advantages for targeting TFs, a feat that is especially difficult to achieve with small molecule inhibitors [112]. Candidate upregulated transcription factors include ZEB1, YAP/TAZ, MRTF-A, Gli-1, CREB, ETS-1, STAT3, TWIST1, HOXC10, EZH2, BMI1, JMJD6, P53, ATF5, REST, SP1, and NFAT [112-128], whereas others such as KLF6 are downregulated [129]. ELK4 downregulation was shown to reduce Mcl-1, an anti-apoptotic protein in GBM, resulting in reduced tumor formation in xenograft models. Transcription elongation factors were also proposed as potential GBM targets as discovered in a siRNA screen [123].

TP53 (p53), a DNA-binding protein and regulator of cell cycle arrest and apoptosis, is an obvious candidate as it is commonly mutated in GBM, often with the acquisition of oncogenic features. In fact, TP53 is the single most frequently mutated gene in GBM [17], with overall mutation frequency of about $30 \%$. The mutations are characteristically rare in the classical subtype; however, their rate exceeds $50 \%$ in the mesenchymal subtype. The mutations are often not only loss-offunction but turning TP53 from tumor suppressor to an oncogene in a dominant-negative fashion. Mutant TP53 typically accumulates to very high levels in GBM, contributing to malignant progression $[130,131]$. Targeting TP53, especially the highly expressed dominant-negative form is difficult with 
small molecule drugs [132]. TP53 reactivation is being attempted with zinc metallochaperone-1, as well as drugs such as APR-246, PK11007, PK7088, and COTI-2. Despite its advantages to target oncogenic TP53, no OT has yet been proposed to our knowledge.

It is presently unclear which transcription factors are the most promising targets, and indeed, many may provide initial treatment response, although a few considerations appear important to overcome GBM recurrence [133]. Tumor heterogeneity is likely to account for treatment failure, both in terms of resistance to chemotherapy and disease recurrence [134]. Understanding expression patterns relative to morphological features will aid the development of therapies that can overcome the inherent resistance of GBM arising from its heterogeneity [133]. GSCs are identified based on their ability of tumor initiation and recognized as more treatment resistant [135]. Highly mobile invading tumor cells are also more likely to survive local treatment including surgery and radiation and initiate recurrence. Finally, random mutations and expression alterations in tumor cells give rise to evolving subpopulations that provide diversity with the potential treatment-resistant tumor cell fractions. These subpopulations are initially colocalized within the tumor and subsequently increase relative to others and migrate to distant sites [136]. Tumor cells are hypothesized to communicate via intercellular microtubes that enhance treatment resistance and invasion [137]. Taken together, successful strategies will effectively target GSCs as well as the highly mobile tumor cells.

\section{Preclinical Studies to Target GSCs by OT}

GSCs are reported to have activated POU3F2, SALL2, SOX2, and OLIG2, all four simultaneously, and in combination, and the inhibition of each one leads to the reversible loss of tumorigenicity [138]. In addition to these presumed driver transcription factors, other signaling pathways are also activated, such as Wnt/ $\beta$-catenin, Notch, PI3K, NF-kB, SHH/GLI, COUPTFII, and JAK/STAT/stathmin [139-144]. Members of the STAT family of transcription factors are of particular interest as key regulators of cell growth, angiogenesis, motility, and immune response [145]. STAT3 is reported to be a strong oncogenic driver of GBM, and CRISPR/Cas9-mediated deletion of STAT3 in a GBM-derived cell line blocked tumorigenesis by specifically eliminating GSCs [116, 146]. Perivascular GSCs are reported to exhibit a proneural expression pattern and have activated EZH2, whereas GSCs in hypoxic regions feature a mesenchymal phenotype and express BMI1 protein. Using genetic or pharmacologic inhibition of both, all GSCs in the tumor were effectively inhibited leading to improved survival in a mouse model [120]. The zinc finger-containing transcription factor Gli-1 is the main transcriptional mediator of the Sonic Hedgehog ( $\mathrm{SHH}$ ) signaling pathway and is highly expressed GBM. siRNA-mediated downregulation of Gli-1 expression resulted in reduced proliferation and increased apoptosis in vitro [147]. MEF/ELF4 was found to be highly expressed in GBM, the level of expression correlated with poor prognosis as well as stem-like cellular characteristics [148]. PRMT5 is a methyltransferase and putative splicing regulator that affects GSC self-renewal. Its expression is also associated with more aggressive disease [149]. Silencing of PRMT5 expression in GBM-derived cell lines results in apoptosis and reduces tumorigeneity in vivo [150]. Knockdown of the ecto-nucleotidase ENPP1 in cultured GSCs induced differentiation, cell cycle arrest, and apoptosis [151].

\section{OT to Modify DNA Methylation and Histone Modification}

Epigenetic regulators have a key role in GBM development demonstrated by the IDH-mutant disease. ING5 has been shown to enhance self-renewal and tumor formation. Such epigenetic regulators are potential targets for treatment [152]. TLX knockdown by siRNA inhibited human GBM tumor formation in mice via upregulation of TET3 expression [153]. AJAP1, a cell junction protein, was found to be deleted or epigenetically silenced in most GBMs, and restoration of expression resulted in decreased tumor cell migration [154]. ARNT2, a HIF family member, is proposed a possible GBM target as the regulator of GBM aggressiveness via histone methylation [155].

\section{Key Aspects of the GBM Tumor Microenvironment Emerge as OT Targets}

Emerging data supports the role of the GBM TME both as enabling disease development and actively supporting GBM cells in progressive disease. GBM TME contains a large number of non-GBM cells, such as macrophages, microglia, myeloid cells, lymphocytes, astrocytes, and endothelial cells. The GBM TME is highly immunosuppressive and actively enhancing GBM growth. Macrophages and microglia appear to constitute substantially to the tumor mass [156]. Inhibition of colony-stimulating factor-1 receptor (CSF-1R) by BLZ945 was shown to block glioma progression [157]. Inhibition of CSF-1R by PLX3397 was reported to reduce tumor cell proliferation and glioma progression in a PDGFB-driven proneural glioma mouse model, although having no direct effect on cultured GBM cells. In contrast, the receptor tyrosine kinase inhibitors dovitinib and vatalanib were effective to reduce GBM cell growth in vivo, but had no anti-tumor effects in vivo [158]. Although the mouse model used in the study rapidly develops resistance to CSF-1R inhibition, combining IGF-1R or PI3K blockade with CSF-1R inhibition delayed resistance and increased survival [156]. Natural killer cells infiltrating the tumor are reported to inhibit GBM growth via secreted TNF- $\alpha$ in response to PDGF-DD, an isoform of 
PDGF, which in turn, is produced by GBM cells. This intrinsic break in GBM growth can be enhanced by $\mathrm{CpG}$ oligonucleotide treatment [159]. Recent evidence suggests that GBMassociated endothelial cells contribute to resistance to VEGF pathway inhibitors by downregulating VEGFR-2, and dual inhibition of VEGFR and PDGFR may overcome this resistance [160]. The collagenase genes MMP1 and MMP13 are overexpressed in 5\% of GBM specimens and promote tumor invasion [161]. NF1 deficiency of GBM is associated with increased tumor-associated macrophages and microglia infiltration [18].

\section{Alternative OT Targets: Splice Regulation, RNA Processing, Combination Therapy to Attack Multiple Signaling Pathways, and Overcoming TMZ Resistance}

Splice-switching oligonucleotides (SSOs) have also been applied to GBM treatment. Of the alternatively spliced Mnk2a/ Mnk2b products, Mnk2a is a tumor suppressor, whereas MnK2b is oncogenic. In U87MG cells, an SSO effectively increased Mnk2a expression although normally the cells express Mnk2b almost exclusively. This led to reduced colony formation in soft agar [162]. A similar approach was applied to Bcl-xL/Bcl-xS splice-switching. Bcl-xL, an anti-apoptotic protein, is preferentially expressed in GBM, whereas the alternatively spliced $\mathrm{Bcl}-\mathrm{xS}$ version is pro-apoptotic and highly efficient to produce programmed cell death. An SSO was tested in commonly used GBM cell lines in vitro [163]. Targeting polypyrimidine tract-binding protein 1 (PTB1) offers a distinct approach to target mRNA splicing and selective modify protein isoforms [164].

Although specific signaling pathway activations are found in subsets of GBM [165], inhibition of such signaling pathways thus far showed disappointing results [166]. Continued efforts are needed to look for effective targets. For example, combination oligonucleotide therapy has the promise of effective growth suppression through pathway inhibition to avoid the emergence of resistant clones although exhibiting tolerable toxicity [167-169]. A test of a target-pair combination approach to block key signal transduction pathways showed that simultaneous knockdown of CK2 $\alpha$ and EGFR/EGFRvIII resulted in downstream target deactivation, reduced GSC marker expression, and prolonged survival in a mouse model [170].

A number of other potential GBM treatment targets are being explored. MGMT is of great interest as the mediator of TMZ resistance of GBM [171, 172]. Targeted depletion of KPNB1, a nuclear protein transport receptor, resulted in efficient upregulation of pro-apoptotic Bcl-2 family members, resulting GBM cell death [173]. There is evidence that neuronal activity may promote GBM growth via neuroligin-3 secretion, offering further potential therapeutic targets [174]. Dopamine receptor D4 antagonists have been identified in a drug screen to selectively kill GBM cells [175], suggesting that elements of the dopamine pathway may be effective targets. RBM14 controls nonhomologous end-joining (NHEJ) DNA repair and knockdown of RBM14 sensitizes glioma spheroids to radiation [176].

RNA processing and specific RNA-binding proteins (RBPs) appear to be significantly altered in GBM and are of interest as potential targets [70,177]. RBPs are regulators of RNA splicing, capping, polyadenylation, transport, decay, localization, and translation. The polypyrimidine tract-binding protein PTBP1 was found to be highly expressed in many GBM specimens, causing aberrant splicing of annexin A7, a tumor suppressor, in turn resulting in enhanced EGFR signaling. PTBP1 expression is low in glial cells and derepressed in GBM as a result of deregulated miR-124 or PTBP1 amplification [178]. Splicing factor hnRNPH is also frequently upregulated in GBM. As a result, the death-domain adaptor protein Insuloma-Glucagonoma protein 20 undergoes erroneous splicing to generate an anti-apoptotic variant, causing absent TNF- $\alpha /$ TRAIL apoptosis signaling [179]. DDX1, an RNA helicase, is overexpressed in a subset of GBM specimens [161]. The conserved RNA-binding protein Musashil is proposed as a major regulator of splicing in GBM cells, affecting cell adhesion, migration, and invasion [180, 181]. Alternative polyadenylation of mRNA transcripts plays a key role in carcinogenesis and was shown to occur in GBM [182]. Better understanding of the mechanism may lead to the identification of potential GBM vulnerabilities. Knockdown of SNRPB, a component of the splicing machinery in a GBM cell line, resulted in apoptosis [183].

Finally, tumor suppressor (TS) genes play an important role in GBM development. CDKN2A is homozygously deleted in $52 \%$, PTEN in $36 \%$, p53 in $35 \%$, and NF1 in $18 \%$ of GBM samples. Restoration of TS expression is being tested for various tumor types [184] and may be applied to GBM. Such an approach, however, would have to overcome several obstacles; a large number of TSs are involved, and some of them have a wide range of inactivating mutations; therefore, therapy must be individualized. Furthermore, restoration of expression needs to be near-universal, or rapid tumor progression would occur. Presently, such barriers to TS reactivations seem insurmountable; however, emerging gene-editing technologies may advance this strategy.

Table 1 presents a summary of select candidate genes for GBM OT that are the most promising to lead to trial candidates, based on the prevalence of alterations and preclinical evidence of efficacy. Prior OT clinical trials conducted for malignancies other than GBM should be both encouraging to the potential of this approach to target disease but also sobering to the task ahead (Table 2). The apparent efficacy to treat lymphoma but not solid tumors highlights the crucial importance of delivery. Experience from these efforts will no doubt help to find an effective OT implementation for GBM. 
Table 1 Candidate mRNAs and protein-coding genes for inhibition therapies in GBM

\begin{tabular}{llll}
\hline mRNA & Dysregulation & Pathway & \\
\hline EGFR & Amplification, mutation & RTK signaling & {$[185-187]$} \\
TERT & Transcriptional activation & Telomere lengthening & {$[188,189]$} \\
STAT3 & Upregulated & Cytokine signaling & {$[81,190,191]$} \\
Gli-1 & Upregulated & Hedgehog signaling & {$[147,192]$} \\
Notch1 & Upregulated & Notch signaling & {$[193,194]$} \\
Myc & Upregulated & Mitogenic signaling & {$[195-197]$} \\
Wnt & Activated & Wingless signaling & {$[198-200]$} \\
PI3K & Activated & Signal transduction & {$[201,202]$} \\
NF-KB & Activated & Cytokine production & {$[168,203]$} \\
EZH2 & Activated, upregulated & Self-renewal & {$[33,120]$} \\
POU3F2 & Activated & Self-renewal & {$[204-206]$} \\
SALL2 & Activated & Self-renewal & {$[204-206]$} \\
SOX2 & Activated & Self-renewal & {$[204-206]$} \\
OLIG2 & Activated & Self-renewal & {$[204-206]$} \\
\hline
\end{tabular}

Targets that appear the most promising to lead to OT-based trials are selected based on the prevalence of alterations and preclinical evidence of feasibility and efficacy

Table 2 OTs in oncology clinical trials: select agents that may be considered for repurposing to GBM

\begin{tabular}{|c|c|c|c|}
\hline Drug & Target & Disease & Result/reference \\
\hline \multicolumn{4}{|l|}{ Phase III } \\
\hline \multirow[t]{3}{*}{ Oblimersen/G3139 } & $\mathrm{Bcl}-2$ & Advanced melanoma & Negative [207] \\
\hline & & CLL & Positive [208] \\
\hline & & Multiple myeloma & Negative [209] \\
\hline Custirsen/OGX-011 & Clusterin & Prostate cancer & Negative $[210,211]$ \\
\hline \multicolumn{4}{|l|}{ Phase II } \\
\hline AZD9150 & STAT3 & Malignant ascites & Unpublished \\
\hline IONIS-STAT3Rx & STAT3 & Advanced cancers & Unpublished \\
\hline Veglin & VEGF & Mesothelioma & Sponsor withdraw support \\
\hline DCR-MYC & Myc & Hepatocellular carcinoma & Unpublished \\
\hline \multirow[t]{4}{*}{ Apatorsen/OGX-427 } & Hsp-27 & Prostate cancer & PFS unchanged but biomarker improved [212] \\
\hline & & Urothelial carcinoma & Nonsignificant improvement in OS [213] \\
\hline & & Urothelial carcinoma & Negative [214] \\
\hline & & Pancreatic cancer & Nonsignificant improvement in PFS/OS [215] \\
\hline \multirow[t]{2}{*}{ LErafAON } & c-Raf & Head and neck cancer & Unpublished \\
\hline & & Clear cell renal cell cancer & Unpublished \\
\hline IMO-2055 & TLR9 & Clear cell renal carcinoma & Unpublished \\
\hline EMD 1201081 & TLR9 & Head and neck cancer & Negative [216] \\
\hline \multirow[t]{3}{*}{ AEG35156 } & XIAP & Hepatocellular carcinoma & Positive [217] \\
\hline & & Acute leukemia & Negative [218] \\
\hline & & Breast/pancreas/NSCLC & Unpublished \\
\hline \multicolumn{4}{|l|}{ Phase I } \\
\hline MTL-CEBPA & $\mathrm{C} / \mathrm{EBP}-\alpha$ & Hepatic carcinoma & Unpublished \\
\hline PNT2258/PNT100 & $\mathrm{Bcl}-2$ & Advanced solid cancers & Mild lymphocyte and platelet count drop [219] \\
\hline EZN-2968 & $\mathrm{HIF}-1 \alpha$ & Advanced solid tumors/lymphoma & Unpublished \\
\hline LErafAON & c-Raf & & Safe and well tolerated [220] \\
\hline AZD4785 & KRAS & Advanced solid tumors & Unpublished \\
\hline ISIS 183750 & eIF4E & Advanced solid tumors & Safe and well tolerated [221] \\
\hline
\end{tabular}

PFS = progression-free survival; OS = overall survival 


\section{MicroRNA Normalization by OT}

\section{Complexity of MiRNA Regulation and Challenges in Identification of Most Efficacious Therapeutic MiRNA for OT Targeting}

MiRNAs are small RNA regulators of various cellular processes that are heavily implicated in cancer and among the most promising targets for the OTs [222, 223]. MiRNAs control gene expression post-transcriptionally, by binding to partly complementary sites in mRNA targets, with sometimes only 6-8 nucleotide binding sufficient for mRNA destabilization and translational repression. Each miRNA can regulate the levels of numerous targets, including the genes that either promote or counteract carcinogenesis. Therefore, miRNAs themselves can exhibit either tumor-promoting and tumorsuppressive properties and were shown to contribute to the development of many cancers. Deregulation of miRNA expression has been associated with cancer initiation, progression, and metastasis; consequently, miRNAs have been proposed as both biomarkers and therapeutic targets for various malignancies [222, 224]. Distinct miRNA signatures also characterize gliomas of high and low grades, and thus, miRNAs present excellent biomarkers for these diseases $[225,226]$. Furthermore, miRNAs regulate all aspects of glioma growth including tumor cell proliferation, invasion, survival, angiogenesis, cancer stem cell properties, immune escape, and therapy resistance (reviewed in Zhang et al. [227]). Many miRNAs have been associated with HGG, and numerous mRNA targets validated to different extent for each of them. It should be noted that because of the complexity of the miRNA regulation, there is a trend in the field to reduce miRNA functions to one or a few selected targets, the approach that rarely reflects the true nature of miRNA regulation. Furthermore, a validated mRNA target in one cell type may not be regulated by the same miRNA in other cell types. Such diversity of miRNA regulation has been observed not only among the cells of different cancers, but also heterogeneous glioma cell lines [228-230]. Consequently, functions of specific miRNAs are often context and cell type dependent and dictated by the balance and stoichiometry of multiple coexpressed targets. For example, miR-17-92 is an established polycistronic oncogene [231], and its inhibition leads to decreased proliferation of glioma spheres in vitro [232]. However, the higher rather than the lower levels of miR-17 are strongly associated with extended survival of GBM patients [71, 233], probably because of its alternative functions in other cells of the GBM microenvironment [234]. Conversely, an established tumor suppressor miR-34a, whose mimic has reached phase I clinical trials for treating select cancers [235], appears as a "risk factor" in GBM [71, 233] and, thus, may not be a therapeutically relevant for this disease. Finally, modulation of some miRNAs, such as miR-148 and miR-26a, may be beneficial for subsets of glioma in a subtype-specific manner [71, 236, 237].

These examples highlight the challenges of identifying the most efficacious therapeutic miRNA candidates for inhibition or supplementation. Although numerous miRNAs have been functionally associated with GBM (reviewed by Zhang et al. [227]), most of them require rigorous follow-up analyses preceding any clinical development. In the following sections, we will focus on several best validated miRNA targets for OT, including tumor-promoting miRNAs that could be inhibited by anti-miRs and tumor-suppressing miRNAs for potential oligonucleotide replacement therapies. Generally, miRNA inhibitors are single-stranded ASO, bearing modifications similar to those utilized in ASO for mRNA targeting. They reduce miRNA levels or activity via RNaseH mechanism or interfere with miRNA incorporation to RICS. Typically, miRNA mimic oligonucleotides are double stranded, principally similar in their design to siRNAs; however, the single-strand design seems also feasible [238]. In this section, we will also list the best validated mRNA targets that mediate miRNA activity in GBM and may provide functional readouts for the efficacy of miRNA modulation by the anti-miRs and mimics.

\section{Key MiRNAs for Inhibition Therapies}

MiR-21 was the first miRNA discovered that was upregulated in GBM [239] and is the most widely studied tumorpromoting miRNA in various cancers. We and others have provided detailed reviews of its expression and cancerassociated functions previously [240, 241]. MiR-21 is encoded in a plastic, frequently activated chromosome $17 q 23$ locus, and its high expression is a characteristic feature of multiple malignancies. In GBM, it has been implicated in tumor cell cycle, survival, invasion, angiogenesis, and therapy resistance via numerous direct targets and downstream signaling pathways [241]. Our early studies have demonstrated that miR-21 regulates more than 500 mRNAs in glioma cells and suggested at least 70 of them as direct targets containing miR21-binding sites [242]. Among the validated direct targets are the tumor suppressor PDCD4, metalloprotease inhibitors RECK and TIMP3 involved in invasiveness and angiogenesis, a molecular core of the apoptosome APAF1, the cell cycle regulator $\mathrm{CDC} 25 \mathrm{~A}$, the transcriptional inhibitor NFIB, a negative regulator of Ras signaling Spry1/2, and insulin-like growth factor (IGF)-binding protein-3 [243, 244]. PTEN and STAT3 have been suggested as additional miR-21 targets, but this is still controversial [245, 246]. Involvement of several key targets in miR-21 tumor-promoting functions has been demonstrated in mouse models in vivo [242, 243, 247]. Altogether, these data provide a strong rationale for miR-21 clinical targeting, alone or in combination with other drugs. Of note, however, miR-21 is highly expressed in various cells and tissues and contributes to immune response and other normal 
functions [241, 248], and the consequences of its local intracranial or systemic inhibition have yet to be assessed.

In addition to cultured glioma cells [87, 249], several studies attempted miR-21 inhibition in established intracranial GBM, using various antagomiRs and delivery techniques. For example, injections of the miR-21 antisense-ODN complex with amphiphilic R3V6 peptide suppressed tumor growth of C6 glioma [250]. A selective small molecule inhibitor of miR-21 maturation (AC1MMYR2), when injected intraperitoneally to mice bearing orthotopic U87 tumors inhibited tumorigenesis [251]. An interesting recent study suggested that selective brain tumor targeting can be achieved with threeway-junction (3WJ)-based RNA nanoparticles, artificially derived from pRNA of bacteriophage phi29 DNA packaging motor. Repeated systemic treatment with the folateconjugated $3 \mathrm{WJ}$ RNP harboring anti-miR-21 8-mer LNA sequence (FA-3WJ-LNA-miR21) targeted orthotopic GBM and reduced tumor growth in a PDX mouse model [252].

The miRNA miR-10b appears to be a very promising miRNA target for malignant gliomas. This miRNA is not expressed in the healthy brain cortex, whereas its high levels appear as the common marker of the malignant state, including both primary and metastatic brain malignancy [253]. Although undetectable in normal glia, neuron, and neuroprogenitor cells, miR-10b gets transcriptionally activated in most gliomas of both low and high grades [70, 253]. Moreover, it appears to elicit tumor "addiction," in that there seems to be no alternative pathway to bypass miR-10b loss [254]. MiR-10b is essential for glioma viability and its inhibition by ASO or deletion by gene editing is detrimental for the tumor but has no obvious negative effects on normal neural cells $[253,254]$. The downstream effects of miR-10b expression involve glioma cell cycle, invasion, and resistance to apoptosis [70, 229, 230, 253, 255-258]. Among its targets are cell cycle inhibitors CDKN1A/p21 and CDKN2A/p16, pro-apoptotic gene BCL2L11/Bim, and MBNL splicing factors [70, 253]. HOXD10, initially also reported as a direct miR-10b target, remains controversial [253, 259]. Notably, despite several validated miR-10b targets, the mechanism of glioma addiction to miR-10b remains largely unknown and involves unconventional mechanisms [70]. A number of formulations and carriers have been tested for anti-miR-10b delivery to cultured glioma cells, including the PLGA nanoparticles [260] and PDGFR-targeted aptamers [84]. Various formulations of miR-10b ASO and delivery routes for orthotopic GBM were explored [70]. This included intratumor injections of lipophilic formulations, convection-enhanced delivery of the cationic LNPs via osmotic pump, and systemic delivery of unformulated stabilized PS 2'-O-MOE anti-miR-10b oligonucleotide. Notably, both local and systemic administration of anti-miR-10b in intracranial glioma models led to the derepression of mRNA targets and slowed down tumor growth. Furthermore, high doses of systemically administered miR-
$10 \mathrm{~b}$ inhibitors (up to $150 \mathrm{mg} / \mathrm{kg}$ ) appear safe in mice [70]. This data encourages further development of both local and systemic miR-10b-targeting therapies.

In addition, our recent work also demonstrates the feasibility of gene-editing strategies for brain tumors in vivo and suggests that CRISPR/Cas9-medited miR-10b gene ablation may provide a new and highly effective therapeutic approach that directly eliminates the key oncogenic dependency of gliomas [254]. Importantly, virus-mediated gene editing of the miR-10b locus is much more efficient in glioma than in normal neuroglial cells that do not express this miRNA. This result suggests a wide therapeutic window for the miR-10bediting systems targeting malignant brain tumors.

The closely related miR-221 and miR-222 paralogue miRNAs are frequently upregulated in gliomas and characterized as an oncogenic cluster. High levels of these miRNAs appear as a strong risk factor associated with shortened survival including both low- and high-grade glioma [71, 261]. Based on TCGA analysis, miR-222 expression correlates with proliferation, anti-apoptosis, and cell migration-related bioterms in gliomas [71]; it promotes glioma cell invasion and confers therapy resistance [261, 262]. Combined inhibition of the two miRNAs with PNAs conjugated with an octaarginine tail promotes apoptosis and sensitized glioma cell lines to TMZ [263]. MiR-221/222 target the cell growth suppressive cyclin-dependent kinase inhibitors CDKN1B/ p2 $7^{\mathrm{Kip} 1}$ and CDKN1C/p57 Kip2 and thereby enable bypassing quiescence [264, 265], along with the mediator of apoptosis PUMA [266]. Other targets associated with the regulation of glioma invasion include the protein tyrosine phosphatase $\mu$ $(\mathrm{PTP} \mu)$ [267] and connexin 43, a tumor suppressor and major component for the establishment of gap junction intercellular communication in glial cells, which is frequently reduced or deleted in high-grade gliomas [268].

Therapeutic inhibition of this cluster has been proposed for various cancers, including prostate, melanoma, hepatocellular carcinoma, and multiple myeloma [269-272]. Intratumor injections of its LNA ASO reduced the growth of subcutaneous U251 glioma [261]. However, to the best of our knowledge, the effects of miR-221/222 inhibition in orthotopic GBM have not yet been investigated. While assessing the therapeutic potential of this approach, future studies should also consider the consequences of miR-221/222 inhibition on the regulation of a putative target MGMT and overall health of normal brain tissues expressing relatively high levels of miR-221/222.

\section{Key MiRNAs for Replacement Therapies}

Although miRNA upregulation in GBM considered is an active process and most consistently upregulated miRNAs exhibit tumor-promoting functions, reduced levels of specific miRNAs in tumor cells can be viewed merely as a consequence of the lost cellular identity. Indeed, the miRNA 
signature of neuronal differentiation is lost in glioma, and the miRNAs implicated in the differentiation of neuroglial lineages are those downregulated in the disease. Therefore, replacement of such molecules may potentially lead to the reduced cycling of tumor cells and differentiation of glioma stem cells. In addition, several miRNAs have been characterized as tumor suppressors that regulate important oncogenic proteins. It should be emphasized that development of potent miRNA mimics for GBM treatments is likely to be even more challenging than miRNA inhibitors, because of the impact of chemical modifications required for efficient tissue distribution, and the productive uptake and stability of the OT on the miRNA activity in target regulation are currently unknown.

One of the most prominent candidates for replacement in gliomas is miR-124, an established neurogenic regulator highly enriched in brain neurons and the miRNA most strongly downregulated in HGGs $([273,274]$ and our unpublished data). MiR-124 is generally one of the best investigated ncRNAs, because of its very high brain-specific expression. Its fundamental role in neuronal differentiation, alongside miR-9/9*, includes the control of chromatin accessibility, DNA methylation, mRNA expression, and alternative splicing to induce a default neuronal state [275-278]. Its loss in glioma is associated with upregulation of numerous validated targets critical for glioma proliferation, stemness, migration, and radio- and chemoresistance. Some of the key miR-124 targets are listed in Table 3. Of note, miR-124 expression exhibits inverse correlation with many of its targets in TCGA glioma specimens, suggesting that, indeed, this miRNA is their prime regulator whose loss in GBM results in the massive derepression of the protumorigenic proteins (our unpublished data).
MiR-124 is one of a few master regulators that not only promotes the neurodifferentiation of normal and glioma stem cells $[274,278]$ but also has a capacity to reprogram human fibroblasts to functional neurons [275, 291]. Its supplementation reduces the ability of tumor cells to survive under oxygen and nutrient deprivation [283]. In addition, miR-124 enhances T-cell effector cytokine production via STAT3 signaling and thereby reverses glioma-mediated immunosuppression [292]. Therefore, both local and systemic administration of miR-124 mimics seem a promising therapeutic for glioma treatments. The efficacy of systemically injected miR-124 encapsulated in bilipid nanoparticles or overexpressed in exosomes has been tested in murine models of GBM and suggested survival benefit [293, 294]. In addition, miR-124 delivery to orthotopic U87 tumors was attempted by intratumor injections of the miR-124-overexpressing mesenchymal stem cells [295, 296]. The therapeutic efficacy of these approaches remains to be established.

MiR-128 is also highly expressed in neurons although it is lost in the early stages of gliomagenesis [290], with promise as a replacement therapy. Inhibiting the glioma cell cycle, GSCs renewal and radioresistance, miR-128 targets epigenetic regulators BMI1 and SUZ12, the key components of PRC1 and PRC2, respectively [290, 297]. It also suppresses mammalian target of rapamycin (mTOR) target p70S6K1 and its downstream signaling molecules such as HIF-1 $\alpha$ and VEGF and, thus, attenuates tumor growth and angiogenesis [298].

Other strong candidates for replacement therapies include miR-7, miR-137, miR-181d, and miR-218 [84, 274, 299, 300]. For example, miR-7, a miRNA characterized as tumor suppressor for multiple cancers, regulates glioma growth and invasions via targeting EGFR, focal adhesion kinase, and IRS-

Table 3 Top candidate miRNAs for inhibition or replacement therapies

\begin{tabular}{|c|c|c|c|}
\hline MicroRNAs dysregulated & Regulated process & Major validated direct mRNA targets in glioma & References \\
\hline \multicolumn{4}{|c|}{ MiRNA for inhibition therapies } \\
\hline MiR-10b & Cell cycle, cell death, invasiveness & $\begin{array}{l}\text { CDKN1A, CDKN2A, BCL2L11/BIM, TFAP2C, } \\
\text { MBNL1-3, APAF }\end{array}$ & {$[70,253,255,279]$} \\
\hline MiR-21 & Migration, invasion, apoptosis, angiogenesis & $\begin{array}{l}\text { PDCD4, RECK, TIMP3, APAF, CDC25, NFIB, } \\
\text { Spry2, IGFBP3 }\end{array}$ & {$[242-244,280]$} \\
\hline MiR-221/222 & Cell cycle, apoptosis, invasiveness & $\begin{array}{l}\text { CDKN1B/p2 } 7^{\text {Kip1 }}, \text { CDKN1C/p57 }{ }^{\text {Kip2 }}, \text { PUMA, } \\
\text { PTP } \mu, \text { Cx } 43\end{array}$ & {$[264-266,268]$} \\
\hline MiR-148a & Stemness, angiogenesis, apoptosis & MIG6, BCL2L11/BIM, FIH1, QKI, SKP1, GADD45 & {$[71,236,281,282]$} \\
\hline \multicolumn{4}{|c|}{ MiRNA for replacement therapies } \\
\hline MiR-124 & $\begin{array}{l}\text { Neurodifferentiation, stemness, proliferation, } \\
\text { migration }\end{array}$ & $\begin{array}{l}\text { CDK6, CDK4, NRAS, PIM3, PTBP1, TEAD1, } \\
\text { ROCK1, LAMB1, IQGAP1, LAMC1, ITGB1 }\end{array}$ & {$[178,283-289]$} \\
\hline MiR-128 & GSC renewal, proliferation, angiogenesis & BMI1, SUZ12, E2F3a, p70S6K1 & {$[290,297,298,387]$} \\
\hline MiR-7 & Proliferation, angiogenesis, drug sensitivity & EGFR, FAK, IRS-1, IRS-2 & {$[301-304]$} \\
\hline MiR-181 & $\begin{array}{l}\text { Proliferation, apoptosis, invasiveness, } \\
\text { drug sensitivity }\end{array}$ & MGMT, K-RAS, BCL-2, KLF6 & {$[306-308]$} \\
\hline MiR-218 & $\begin{array}{l}\text { Invasiveness, apoptosis, chemosensitivity, } \\
\text { angiogenesis }\end{array}$ & EGFR, PLC $\gamma 1$, PIK3C2A, ARAF, ECOP, LEF1 & {$[299,300,388]$} \\
\hline MiR-137 & Proliferation, neurodifferentiation, invasion & CDK6, COX-2, PTVP-1, YBX1, CDC42, c-KIT & {$[84,274,389-391]$} \\
\hline
\end{tabular}


1, IRS-2, and other genes, and downstream Akt pathway [301, 302]. It modulates angiogenesis, and its systemic administration in biodegradable nanoparticles targeting both EC and tumor cells reduces angiogenesis and tumor proliferation in glioblastoma xenografts [303]. MiR-7 was also identified as a potent sensitizer for TRAIL-induced apoptosis in GBM cells [304]. miR-181d, whose reduced expression is strongly associated with poor GBM survival [71], was proposed as a tumor suppressor for gliomas. It regulates the expression of critical GBM-driving genes such as MGMT, K-Ras, and Bcl-2 [305, 306]. Other miR-181 family members may contribute to TMZ sensitivity of glioma [307] and increased permeability of the blood-tumor barrier by targeting transcription factor Kruppellike factor 6 [308].

Of note, many additional miRNAs have been suggested as either tumor promoting or suppressive for gliomas (reviewed in Zhang et al. [227]), or contributing to chemo- and radioresistance of HGGs [309]. However, the data is often insufficient or inconsistent to move the candidates to a more advanced preclinical stage. For example, miR-182 appears protective against glioma based on the TCGA analysis [71, 310]; it targets oncogenes such as c-Met, HIF2A, and Bcl2L12, it sensitized glioma to therapy-induced apoptosis, and its intravenous administration in SNA nanoparticles reduces tumor burden and increases the survival of mice with the orthotopic GBM [310, 311]. However, the same miRNA has oncogenic and metastatic properties in multiple other cancers, including medulloblastoma [312-314]. It also triggers TGF- $\beta 1$-dependent NF- $\mathrm{KB}$ induction in glioma cells and provokes a more aggressive glioma phenotype by targeting the deubuiquitinase CYLB and protocadherin-8 [315, 316]. Such results reflect the high complexity and context-dependent functions of miRNAs, pointing to important roles of the tumor microenvironment and the tumor subtype-specific genetic landscape in shaping miRNA responses. It also highlights the requirement for diverse in-depth preclinical studies utilizing heterogeneous GBM models and leading to miRNA-based personalized OT medicine. Table 3 lists select candidate miRNAs for GBM OT that are the most promising to lead to trial candidates, based on the prevalence of alterations and preclinical evidence of efficacy.

\section{LncRNA}

The vast majority of the human genome is transcribed into various classes of ncRNAs, including diverse regulatory species, whereas mRNA accounts for only a small part of human transcriptome. Among the ncRNAs, in addition to miRNAs, are thousands of long noncoding RNA (lncRNA) species. These transcripts are longer than $200 \mathrm{nt}$ and transcribed in sense or antisense orientation to protein-coding genes, or within intergenic regions. Many lncRNAs are expressed in a highly tissue-specific manner and dysregulated in cancer. Strikingly, $40 \%$ of human lncRNAs (equivalent to 4000-20,000 lncRNA genes) are expressed specifically in the brain [317], and many of them exhibit dynamic spatiotemporal patterns. However, only a small subset of them has been explored thus far, opening up an exciting new area for research and potential therapeutic interventions. Unlike miRNAs, IncRNAs may operate via multiple molecular mechanisms that include chromatin remodeling, transcriptional interference, miRNA and RBP sequestration, modulation of splicing and translation, protein scaffolding, and others [318]. It is, thus, important to consider subcellular distribution, compartmentalization, and molecular partners of IncRNAs for their targeting, as many (if not most) of them operate in the nuclear domain or protein complexes not easily accessible by traditional RNA-targeting machineries such as RNAi $[318,319]$. Additional challenge in studying lncRNAs is associated with their characteristic species specificity that limits cellular and animal modeling of their functions. Significant efforts are required to better understand the biology and functional diversity of IncRNAs, improve and standardize lncRNA nomenclature and databases, and reveal their therapeutic potential.

Similarly, substantial efforts will be required to understanding the rules of the oligonucleotide-mediated lncRNA targeting and optimization of the corresponding OTs. Generally, a sequence-specific design of ASOs and siRNAs utilized for mRNA targeting has been also applied for the IncRNAs [320]. Thus, degradation of lncRNAs has been achieved via RNase H cleavage and RNAi machinery, correspondingly. As a remarkable example, application of combinatorial 2'-O-MOE DNA ASOs resulted in the efficient longterm knockdown of a long nuclear UBE3A antisense transcript $(1000 \mathrm{~kb})$ in cultured neurons and CNS of an Angelman syndrome mouse model [321]. LNA-, PNA-, and SNA-based OTs have been also proposed for targeting cytosolic and nuclear lncRNAs [322-324]. Of note, although RNAi is viewed as a largely cytosolic pathway, siRNAs have been also shown to target nuclear IncRNAs both transcriptionally and post-transcriptionally $[325,326]$. Overall, although multiple reports led to the recognition of lncRNAs as compelling targets for OT, no study has yet systematically tackled the unique technical challenges associated with silencing IncRNAs, which are shorter, of lower abundance, more structured, and more likely to contain repeats than mRNA [327, 328]. Development of the therapeutic targeting of IncRNA will undoubtfully require detailed mechanistic studies of the individual lncRNA candidates and their interacting partners. It will also benefit from the research addressing off-target effects associated with targeting lncRNA and the development of new bioinformatics and computational tools enabling the assessment and prediction of such off-targets. 
With the research of lncRNAs in glioma exponentially growing in the past 5 years, lncRNAs have been implicated in glioma growth, invasion, stem cell maintenance, angiogenesis, and BBB penetrance [329]. Nevertheless, it might be still premature to propose the candidate lncRNAs for therapeutic targeting; we will thus list only on a few lncRNAs that are upregulated in HGGs, associated with the disease progression and prognosis [330], and have been reported as oncogenic in several independent publications. The most studied among them is HOTAIR, a HOX transcript antisense RNA that promotes glioma cell cycle, growth, and angiogenesis [331, 332]. The mechanism of its function in glioma is not fully investigated and may include EZH2-dependent epigenetic regulation [333], as well as regulation of $\beta$-catenin signaling [334] and perturbed miRNA binding [335-337]. Another lncRNA H19 is processed from the H19-IGF2 loci, can be induced by c-myc and HIF $1 \alpha$, and is upregulated in glioma and other malignancies [338, 339]. It has been implicated in tumor invasion, angiogenesis, and resistance to $\mathrm{TMZ}$ [340-344]. MiRNA binding and sequestration by H19 has been proposed as the major mechanism underlying its functions; however, additional studies are required to further evaluate its role in gliomagenesis and therapeutic potential. CRNDE, a lncRNA initially discovered in colorectal cancer, also appears highly upregulated and associated with disease progression in gliomas [345]. The proposed mechanisms of CRNDE-induced glioma growth include miR-384 targeting and its downstream signaling [346], as well as inhibition of mTOR pathway via P70S6K phosphorylation [347]. LncRNA taurine upregulated 1 (TUG1) coordinately promotes GSC self-renewal by antagonizing miR-145 in the cytoplasm and recruiting polycomb via YY1 binding to repress differentiation genes in the nucleus [348]. It has also been associated with glioma angiogenesis and VEGFA expression [349]. Additional interesting, potentially glioma growth-promoting lncRNAs that require further exploration are NEAT1 $[350,351]$, XIST [352, 353], FOXM1-AS [354], CCAT1/2 [355, 356], EXONEXIN [357], and lncRNAs expressed from the HOXA locus $[358,359]$. In addition, controversial evidence suggests both oncogenic and tumor-suppressive functions for specific highly abundant glioma lncRNAs such as the key invasion and metastasis-associated MALAT1 [360, 361], indicating a need in the careful follow-up investigations.

Notably, very little effort has thus far been reported to target lncRNA in the orthotopic glioma models. Practically all animal studies relied on the ex vivo manipulations to examine the effects of IncRNA on the growth of glioma tumors. In this venue, a notable experiment was reported by Katsushima et al., in which an ASO-targeting TUG1 delivered in cyclic Arg-Gly-Asp (cRGD) peptide-conjugated polymeric micelles was intravenously injected to mice bearing the orthotopic proneural GBM [348]. The treatment has been administered at $1 \mathrm{mg} / \mathrm{kg}$ per day over 4 weeks, twice a week, leading to the induction of GSC differentiation and efficient repression of tumor growth. Although the advancement of OT targeting the tumor-promoting lncRNA only recently emerged as an important new research avenue for exploration, it may require special considerations for the development of chemistries and formulations efficacious for this new class of therapeutic targets, governing pleiotropic functions in both nuclear and cytosolic compartments.

It is also worth noting the expression of numerous putative tumor suppressor lncRNAs in glioma (reviewed in Peng et al. [329]). Some of them have been implicated in tethering and, thereby, reducing functional activity of oncogenic miRNAs; for example, lncRNAs CASC2 and Gas5 mediate the repression of tumorigenic miR-21 and miR-222, correspondingly $[362,363]$. Activation of such TS IncRNA should be considered as additional therapeutic approach, and oligonucleotides could be leveraged for the gene-editing strategies aimed at such activation, as outlined below.

\section{Immunomodulatory Cancer Therapy}

Efforts to apply OT therapy to initiate antitumor immunity are overshadowed by the recent achievements with checkpoint inhibitor antibodies and T cells with engineered chimeric antigen receptor (CAR-T), in B-cell lymphoblastic leukemia [364], non-Hodgkin lymphoma [365], esophagogastric cancer [366], non-small cell lung cancer [367], melanoma [368], and renal cancer [369]. Despite these successes, the efficacy of checkpoint inhibitors [370] or CAR-T [371-375] in GBM has not been demonstrated thus far. There is preclinical data for EGFR and HER2 CAR-T therapy for pediatric brain tumors and clinical trials are being carried out [376]. Although CD19 CAR-T had shown strong efficacy in non-Hodgkin lymphoma and B-cell lymphoblastic leukemia, up to $40 \%$ of patients developed neurotoxicity of various severity, termed CAR-T cell-related encephalopathy syndrome (CRES) [364]. It is currently unclear if there is a therapeutic window for GBM CAR-T, or indeed, any immunostimulatory treatment given the presumably even higher risk of CRES. Nevertheless, testing of various ways to achieve antitumor immune response is being explored. MiR-17-92 expression in T cells enhances T-cell survival and interferon production [377]. CRISPR/Cas9-mediated knockout of DGK was found to improve antitumor T-cell activity [378]. As mentioned before, $\mathrm{CpG}$ oligonucleotide treatment of tumor-associated NK cells resulted in reduced tumor growth [159]. Stimulation of the innate immune receptors MDA5 or RIG-I with their natural ligands $\mathrm{p}(\mathrm{I}: \mathrm{C})$ and 3pRNA also improved antitumor activity [379]. 


\section{Expanding the Universe: OT Guides for Genome Editing}

The OT has a remarkable potential to broaden the space of potential targets for gliomas and other CNS disorders, to include mRNAs encoding diverse protein factors, along with various classes of regulatory RNAs. Moreover, and perhaps most exciting, is that in addition to the traditional RNA-targeting applications of the OTs (e.g., ASO, SSO, siRNAs, miRNA modulators), recent studies indicate that oligonucleotides may activate gene transcription [380] and provide advantageous guides for genome-editing technologies as well [381]. Plasmid and viral delivery systems for Cas9-sgRNA applications in vivo have multiple limitations associated with system design, efficacy, and durability of exposure to the editing machinery. In contrast, chemically synthesized oligonucleotide gRNAs could enhance genome editing activity by reducing susceptibility to nuclease degradation and at the same time minimizing the exposure to editing machinery and thus off-target effects and leading to improved therapeutic efficacy [381-385]. A recent study of lipid nanoparticle formulations of such gRNAs and mRNA encoding Cas9 has already demonstrated clinically relevant levels of genome editing in vivo [386], highlighting the therapeutic potential of this system. As genome editing may provide a unifying strategy for correcting mutations, deleting oncogenes, activating tumor suppressors, and potentially also editing regulatory elements and $3 \mathrm{D}$ genome architecture, its applications to human diseases are practically unlimited. Our recent work demonstrated both feasibility and efficacy of CRISPR-Cas9 gene editing (of miR-10b) in intracranial GBM models [254] and, thereby, opened up the area of therapeutic gene editing for malignant brain tumors. Future studies will investigate the applications of oligonucleotide-guided gene editing for correcting the key aberrations underlying gliomagenesis at the levels of genome and transcriptome. Correcting mutations (e.g., in EGFR, IDH, P53), modifying promoter marks (e.g., MGMT methylation), and editing genetic and epigenetic architecture to normalize gene expression, as well as deleting mRNA and ncRNA oncogenes at the genomic level, may provide alternative and complementary OT-based strategies to those targeting RNA, along with the more conventional therapies.

Acknowledgments This work was supported by R01 CA215072, R21 NS098051, U19 CA179563 by the United States National Institutes of Health and National Institutes of Health Common Fund, through the Office of Strategic Coordination/Office of the National Institutes of Health Director. We thank Dr. Rosalia Rabinovsky for assistance with figure preparation and Ms. Joan Swan for administrative support. We extend our thanks to members of Krichevsky Laboratory for helpful discussions. We acknowledge that not all relevant publications could be overviewed and cited in this manuscript because of space limitations, and apologize for those not included.
Open Access This article is distributed under the terms of the Creative Commons Attribution 4.0 International License (http:// creativecommons.org/licenses/by/4.0/), which permits unrestricted use, distribution, and reproduction in any medium, provided you give appropriate credit to the original author(s) and the source, provide a link to the Creative Commons license, and indicate if changes were made.

Publisher's Note Springer Nature remains neutral with regard to jurisdictional claims in published maps and institutional affiliations.

\section{References}

1. Miller JJ, Wen PY. Emerging targeted therapies for glioma. Expert Opin Emerg Drugs 2016;21:441-452.

2. Lieberman F. Glioblastoma update: molecular biology, diagnosis, treatment, response assessment, and translational clinical trials. F1000Res 2017;6:1892.

3. De Vleeschouwer S, editor. Glioblastoma. Brisbane (AU) 2017. Available online at: https://codonpublications.com/index.php/ codon/catalog/book/35. Accessed 27 Dec 2018.

4. Wen PY, Chang SM, Lamborn KR, et al. Phase I/II study of erlotinib and temsirolimus for patients with recurrent malignant gliomas: North American Brain Tumor Consortium trial 04-02. Neuro Oncol 2014;16:567-578.

5. Cancer Genome Atlas Research N. Comprehensive genomic characterization defines human glioblastoma genes and core pathways. Nature 2008;455:1061-1068.

6. Cancer Genome Atlas Research N, Brat DJ, Verhaak RG, et al. Comprehensive, integrative genomic analysis of diffuse lowergrade gliomas. N Engl J Med 2015;372:2481-2498.

7. Ohgaki $\mathrm{H}$, Kleihues $\mathrm{P}$. The definition of primary and secondary glioblastoma. Clin Cancer Res 2013;19:764-772.

8. Louis DN, Perry A, Reifenberger G, et al. The 2016 World Health Organization classification of tumors of the central nervous system: a summary. Acta Neuropathol 2016;131:803-820.

9. Balss J, Meyer J, Mueller W, et al. Analysis of the IDH1 codon 132 mutation in brain tumors. Acta Neuropathol 2008;116:597-602.

10. Yan $\mathrm{H}$, Parsons DW, Jin G, et al. IDH1 and IDH2 mutations in gliomas. N Engl J Med 2009;360:765-773.

11. Watanabe T, Nobusawa S, Kleihues P, Ohgaki H. IDH1 mutations are early events in the development of astrocytomas and oligodendrogliomas. Am J Pathol 2009;174:1149-1153.

12. Hartmann C, Meyer J, Balss J, et al. Type and frequency of IDH1 and IDH2 mutations are related to astrocytic and oligodendroglial differentiation and age: a study of 1,010 diffuse gliomas. Acta Neuropathol 2009;118:469-474.

13. Zhao S, Lin $\mathrm{Y}, \mathrm{Xu} \mathrm{W}$, et al. Glioma-derived mutations in IDH1 dominantly inhibit IDH1 catalytic activity and induce HIF-1alpha. Science 2009;324:261-265.

14. $\mathrm{Xu} \mathrm{W}$, Yang H, Liu Y, et al. Oncometabolite 2-hydroxyglutarate is a competitive inhibitor of alpha-ketoglutarate-dependent dioxygenases. Cancer Cell 2011;19:17-30.

15. Lu C, Ward PS, Kapoor GS, et al. IDH mutation impairs histone demethylation and results in a block to cell differentiation. Nature 2012;483:474-478.

16. Eckel-Passow JE, Lachance DH, Molinaro AM, et al. Glioma groups based on $1 \mathrm{p} / 19 \mathrm{q}, \mathrm{IDH}$, and TERT promoter mutations in tumors. N Engl J Med 2015;372:2499-2508.

17. Verhaak RG, Hoadley KA, Purdom E, et al. Integrated genomic analysis identifies clinically relevant subtypes of glioblastoma characterized by abnormalities in PDGFRA, IDH1, EGFR, and NF1. Cancer Cell 2010;17:98-110. 
18. Wang $\mathrm{Q}, \mathrm{Hu} \mathrm{B}, \mathrm{Hu} \mathrm{X}$, et al. Tumor evolution of glioma-intrinsic gene expression subtypes associates with immunological changes in the microenvironment. Cancer Cell 2017;32:42-56 e46.

19. Thiery JP. Epithelial-mesenchymal transitions in tumour progression. Nat Rev Cancer 2002;2:442-454.

20. Ceccarelli M, Barthel FP, Malta TM, et al. Molecular profiling reveals biologically discrete subsets and pathways of progression in diffuse glioma. Cell 2016;164:550-563.

21. Killela PJ, Reitman ZJ, Jiao Y, et al. TERT promoter mutations occur frequently in gliomas and a subset of tumors derived from cells with low rates of self-renewal. Proc Natl Acad Sci U S A 2013;110:6021-6026.

22. Horn S, Figl A, Rachakonda PS, et al. TERT promoter mutations in familial and sporadic melanoma. Science 2013;339:959-961.

23. Bollam SR, Berens ME, Dhruv HD. When the ends are really the beginnings: targeting telomerase for treatment of GBM. Curr Neurol Neurosci Rep 2018;18:15.

24. Marian CO, Cho SK, McEllin BM, et al. The telomerase antagonist, imetelstat, efficiently targets glioblastoma tumor-initiating cells leading to decreased proliferation and tumor growth. Clin Cancer Res 2010;16:154-163.

25. Salloum R, Hummel TR, Kumar SS, et al. A molecular biology and phase II study of imetelstat (GRN163L) in children with recurrent or refractory central nervous system malignancies: a pediatric brain tumor consortium study. J Neurooncol 2016;129:443-451.

26. Sturm D, Bender S, Jones DT, et al. Paediatric and adult glioblastoma: multiform (epi)genomic culprits emerge. Nat Rev Cancer 2014;14:92-107.

27. Gusyatiner O, Hegi ME. Glioma epigenetics: from subclassification to novel treatment options. Semin Cancer Biol 2018;51:50-58.

28. Pandith AA, Qasim I, Zahoor W, et al. Concordant association validates MGMT methylation and protein expression as favorable prognostic factors in glioma patients on alkylating chemotherapy (Temozolomide). Sci Rep 2018;8:6704.

29. Lalezari S, Chou AP, Tran A, et al. Combined analysis of O6methylguanine-DNA methyltransferase protein expression and promoter methylation provides optimized prognostication of glioblastoma outcome. Neuro Oncol 2013;15:370-381.

30. Hoffmann A, Zimmermann CA, Spengler D. Molecular epigenetic switches in neurodevelopment in health and disease. Front Behav Neurosci 2015;9:120.

31. de Vries NA, Hulsman D, Akhtar W, et al. Prolonged Ezh2 depletion in glioblastoma causes a robust switch in cell fate resulting in tumor progression. Cell Rep 2015;10:383-397.

32. Kim E, Kim M, Woo DH, et al. Phosphorylation of EZH2 activates STAT3 signaling via STAT3 methylation and promotes tumorigenicity of glioblastoma stem-like cells. Cancer Cell 2013;23: 839-852.

33. Suva ML, Riggi N, Janiszewska M, et al. EZH2 is essential for glioblastoma cancer stem cell maintenance. Cancer Res 2009;69: 9211-9218.

34. Sturm D, Witt H, Hovestadt V, et al. Hotspot mutations in H3F3A and IDH1 define distinct epigenetic and biological subgroups of glioblastoma. Cancer Cell 2012;22:425-437.

35. Gallo M, Coutinho FJ, Vanner RJ, et al. MLL5 orchestrates a cancer self-renewal state by repressing the histone variant $\mathrm{H} 3.3$ and globally reorganizing chromatin. Cancer Cell 2015;28:715-729.

36. Flavahan WA, Drier Y, Liau BB, et al. Insulator dysfunction and oncogene activation in IDH mutant gliomas. Nature 2016;529: $110-114$.

37. Watson LA, Wang X, Elbert A, et al. Dual effect of CTCF loss on neuroprogenitor differentiation and survival. J Neurosci 2014;34: 2860-2870.

38. Brennan CW, Verhaak RG, McKenna A, et al. The somatic genomic landscape of glioblastoma. Cell 2013;155:462-477.
39. Chow RD, Guzman CD, Wang G, et al. AAV-mediated direct in vivo CRISPR screen identifies functional suppressors in glioblastoma. Nat Neurosci 2017;20:1329-1341.

40. Dhillon S. Ivosidenib: first global approval. Drugs 2018;78:15091516.

41. Williams MJ, Singleton WG, Lowis SP, Malik K, Kurian KM. Therapeutic targeting of histone modifications in adult and pediatric high-grade glioma. Front Oncol 2017;7:45.

42. Baker SJ, Ellison DW, Gutmann DH. Pediatric gliomas as neurodevelopmental disorders. Glia 2016;64:879-895.

43. Zhang J, Yao TW, Hashizume R, et al. Combined BRAF(V600E) and MEK blockade for BRAF(V600E)-mutant gliomas. J Neurooncol 2017;131:495-505.

44. Dodgshun AJ, SantaCruz N, Hwang J, et al. Disseminated glioneuronal tumors occurring in childhood: treatment outcomes and BRAF alterations including V600E mutation. J Neurooncol 2016;128:293-302.

45. Wurster CD, Ludolph AC. Antisense oligonucleotides in neurological disorders. Ther Adv Neurol Disord 2018;11:1756286418776932.

46. Schoch KM, Miller TM. Antisense oligonucleotides: translation from mouse models to human neurodegenerative diseases. Neuron 2017;94:1056-1070.

47. Geary RS, Norris D, Yu R, Bennett CF. Pharmacokinetics, biodistribution and cell uptake of antisense oligonucleotides. Adv Drug Deliv Rev 2015;87:46-51.

48. Ly CV, Miller TM. Emerging antisense oligonucleotide and viral therapies for amyotrophic lateral sclerosis. Curr Opin Neurol 2018;31:648-654.

49. van Roon-Mom WMC, Roos RAC, de Bot ST. Dose-dependent lowering of mutant huntingtin using antisense oligonucleotides in Huntington disease patients. Nucleic Acid Ther 2018;28:59-62.

50. Lunn MR, Wang CH. Spinal muscular atrophy. Lancet 2008;371: 2120-2133.

51. Finkel RS, Chiriboga CA, Vajsar J, et al. Treatment of infantileonset spinal muscular atrophy with nusinersen: a phase 2, openlabel, dose-escalation study. Lancet 2016;388:3017-3026.

52. Chiriboga CA, Swoboda KJ, Darras BT, et al. Results from a phase 1 study of nusinersen (ISIS-SMN(Rx)) in children with spinal muscular atrophy. Neurology 2016;86:890-897.

53. Grossman SA, Alavi JB, Supko JG, et al. Efficacy and toxicity of the antisense oligonucleotide aprinocarsen directed against protein kinase $\mathrm{C}$-alpha delivered as a 21-day continuous intravenous infusion in patients with recurrent high-grade astrocytomas. Neuro Oncol 2005;7:32-40.

54. Dean NM, McKay R. Inhibition of protein kinase C-alpha expression in mice after systemic administration of phosphorothioate antisense oligodeoxynucleotides. Proc Natl Acad Sci U S A 1994;91:11762-11766.

55. Yazaki T, Ahmad S, Chahlavi A, et al. Treatment of glioblastoma U-87 by systemic administration of an antisense protein kinase Calpha phosphorothioate oligodeoxynucleotide. Mol Pharmacol 1996;50:236-242.

56. Bogdahn U, Hau P, Stockhammer G, et al. Targeted therapy for high-grade glioma with the TGF-beta2 inhibitor trabedersen: results of a randomized and controlled phase Ilb study. Neuro Oncol 2011;13:132-142.

57. Hau P, Jachimczak P, Schlingensiepen R, et al. Inhibition of TGFbeta2 with AP 12009 in recurrent malignant gliomas: from preclinical to phase I/II studies. Oligonucleotides 2007;17:201-212.

58. Schlingensiepen KH, Schlingensiepen R, Steinbrecher A, et al. Targeted tumor therapy with the TGF-beta 2 antisense compound AP 12009. Cytokine Growth Factor Rev 2006;17:129-139.

59. Joseph JV, Balasubramaniyan V, Walenkamp A, Kruyt FA. TGFbeta as a therapeutic target in high grade gliomas - promises and challenges. Biochem Pharmacol 2013;85:478-485. 
60. Schlingensiepen R, Goldbrunner M, Szyrach MN, et al. Intracerebral and intrathecal infusion of the TGF-beta 2-specific antisense phosphorothioate oligonucleotide AP 12009 in rabbits and primates: toxicology and safety. Oligonucleotides 2005;15: 94-104.

61. Wick W, Weller M. Trabedersen to target transforming growth factor-beta: when the journey is not the reward, in reference to Bogdahn et al. (Neuro-Oncology 2011;13:132-142). Neuro Oncol 2011;13:559-560; author reply 561-552.

62. Chamberlain MC. Convection-enhanced delivery of a transforming growth factor-beta2 inhibitor trabedersen for recurrent high-grade gliomas: efficacy real or imagined?, in reference to Bogdahn et al. (Neuro-Oncology 2011;13:132-142). Neuro Oncol 2011;13:558-559; author reply 561-552.

63. Frei K, Gramatzki D, Tritschler I, et al. Transforming growth factor-beta pathway activity in glioblastoma. Oncotarget 2015;6: 5963-5977.

64. Hardee ME, Marciscano AE, Medina-Ramirez CM, et al. Resistance of glioblastoma-initiating cells to radiation mediated by the tumor microenvironment can be abolished by inhibiting transforming growth factor-beta. Cancer Res 2012;72:4119-4129.

65. Ursu R, Carpentier A, Metellus P, et al. Intracerebral injection of $\mathrm{CpG}$ oligonucleotide for patients with de novo glioblastoma - a phase II multicentric, randomised study. Eur J Cancer 2017;73:30-37.

66. Carpentier A, Metellus P, Ursu R, et al. Intracerebral administration of $\mathrm{CpG}$ oligonucleotide for patients with recurrent glioblastoma: a phase II study. Neuro Oncol 2010;12:401-408.

67. McNeill RS, Vitucci M, Wu J, Miller CR. Contemporary murine models in preclinical astrocytoma drug development. Neuro Oncol 2015;17:12-28.

68. Broekman ML, Maas SLN, Abels ER, et al. Multidimensional communication in the microenvirons of glioblastoma. Nat Rev Neurol 2018;14:482-495.

69. Osborn MF, Coles AH, Golebiowski D, et al. Efficient gene silencing in brain tumors with hydrophobically modified siRNAs. Mol Cancer Ther 2018;17:1251-1258.

70. Teplyuk NM, Uhlmann EJ, Gabriely G, et al. Therapeutic potential of targeting microRNA-10b in established intracranial glioblastoma: first steps toward the clinic. EMBO Mol Med 2016;8: 268-287.

71. Wong HA, Fatimy RE, Onodera C, et al. The Cancer Genome Atlas analysis predicts microRNA for targeting cancer growth and vascularization in glioblastoma. Mol Ther 2015;23:1234-1247.

72. Khvorova A, Watts JK. The chemical evolution of oligonucleotide therapies of clinical utility. Nat Biotechnol 2017;35:238-248.

73. Lima JF, Cerqueira L, Figueiredo C, Oliveira C, Azevedo NF. Anti-miRNA oligonucleotides: a comprehensive guide for design. RNA Biol 2018;15:338-352.

74. Khorkova O, Wahlestedt C. Oligonucleotide therapies for disorders of the nervous system. Nat Biotechnol 2017;35:249-263.

75. Evers MM, Toonen LJ, van Roon-Mom WM. Antisense oligonucleotides in therapy for neurodegenerative disorders. Adv Drug Deliv Rev 2015;87:90-103.

76. Delac M, Motaln H, Ulrich H, Lah TT. Aptamer for imaging and therapeutic targeting of brain tumor glioblastoma. Cytometry A 2015;87:806-816.

77. Ireson CR, Kelland LR. Discovery and development of anticancer aptamers. Mol Cancer Ther 2006;5:2957-2962.

78. Cheng Y, Zhao G, Zhang S, et al. AS1411-induced growth inhibition of glioma cells by up-regulation of p53 and downregulation of Bcl-2 and Akt1 via nucleolin. PLoS One 2016;11: e0167094.

79. Guo J, Gao X, Su L, et al. Aptamer-functionalized PEG-PLGA nanoparticles for enhanced anti-glioma drug delivery. Biomaterials 2011;32:8010-8020.
80. Amero P, Esposito CL, Rienzo A, et al. Identification of an interfering ligand aptamer for EphB2/3 receptors. Nucleic Acid Ther 2016;26:102-110.

81. Esposito CL, Nuzzo S, Catuogno S, et al. STAT3 gene silencing by aptamer-siRNA chimera as selective therapeutic for glioblastoma. Mol Ther Nucleic Acids 2018;10:398-411.

82. Kim Y, Wu Q, Hamerlik P, et al. Aptamer identification of brain tumor-initiating cells. Cancer Res 2013;73:4923-4936.

83. Monaco I, Camorani S, Colecchia D, et al. Aptamer functionalization of nanosystems for glioblastoma targeting through the blood-brain barrier. J Med Chem 2017;60:4510-4516.

84. Esposito CL, Nuzzo S, Kumar SA, et al. A combined microRNAbased targeted therapeutic approach to eradicate glioblastoma stem-like cells. J Control Release 2016;238:43-57.

85. Lepinoux-Chambaud C, Eyer J. The NFL-TBS.40-63 antiglioblastoma peptide enters selectively in glioma cells by endocytosis. Int J Pharm 2013;454:738-747.

86. Higa M, Katagiri C, Shimizu-Okabe C, et al. Identification of a novel cell-penetrating peptide targeting human glioblastoma cell lines as a cancer-homing transporter. Biochem Biophys Res Commun 2015;457:206-212.

87. Zhang Y, Kollmer M, Buhrman JS, Tang MY, Gemeinhart RA. Arginine-rich, cell penetrating peptide-anti-microRNA complexes decrease glioblastoma migration potential. Peptides 2014;58:83-90.

88. Khormaee S, Choi Y, Shen MJ, et al. Endosomolytic anionic polymer for the cytoplasmic delivery of siRNAs in localized in vivo applications. Adv Funct Mater 2013;23:1-18.

89. Freimann K, Arukuusk P, Kurrikoff K, et al. Optimization of in vivo DNA delivery with NickFect peptide vectors. J Control Release 2016;241:135-143.

90. Dudley A, Sater M, Le PU, et al. DRR regulates AKT activation to drive brain cancer invasion. Oncogene 2014;33:4952-4960.

91. Arnold AE, Malek-Adamian E, Le PU, et al. Antibody-antisense oligonucleotide conjugate downregulates a key gene in glioblastoma stem cells. Mol Ther Nucleic Acids 2018;11:518-527.

92. Carpentier A, Canney M, Vignot A, et al. Clinical trial of bloodbrain barrier disruption by pulsed ultrasound. Sci Transl Med 2016;8:343re342.

93. Zhao G, Huang Q, Wang F, et al. Targeted shRNA-loaded liposome complex combined with focused ultrasound for blood brain barrier disruption and suppressing glioma growth. Cancer Lett 2018:418:147-158.

94. Gooding M, Malhotra M, McCarthy DJ, et al. Synthesis and characterization of rabies virus glycoprotein-tagged amphiphilic cyclodextrins for siRNA delivery in human glioblastoma cells: in vitro analysis. Eur J Pharm Sci 2015;71:80-92.

95. Kumar P, Wu H, McBride JL, et al. Transvascular delivery of small interfering RNA to the central nervous system. Nature 2007;448:39-43.

96. Saraiva C, Praca C, Ferreira R, et al. Nanoparticle-mediated brain drug delivery: overcoming blood-brain barrier to treat neurodegenerative diseases. J Control Release 2016;235:34-47.

97. Neves AR, Queiroz JF, Weksler B, et al. Solid lipid nanoparticles as a vehicle for brain-targeted drug delivery: two new strategies of functionalization with apolipoprotein E. Nanotechnology 2015;26:495103.

98. Bockenhoff A, Cramer S, Wolte P, et al. Comparison of five peptide vectors for improved brain delivery of the lysosomal enzyme arylsulfatase A. J Neurosci 2014;34:3122-3129.

99. Ruan S, Yuan M, Zhang L, et al. Tumor microenvironment sensitive doxorubicin delivery and release to glioma using angiopep-2 decorated gold nanoparticles. Biomaterials 2015;37:425-435.

100. Clark AJ, Davis ME. Increased brain uptake of targeted nanoparticles by adding an acid-cleavable linkage between transferrin and the nanoparticle core. Proc Natl Acad Sci U S A 2015;112:1248612491. 
101. Lozada-Delgado EL, Grafals-Ruiz N, Vivas-Mejia PE. RNA interference for glioblastoma therapy: innovation ladder from the bench to clinical trials. Life Sci 2017;188:26-36.

102. Costa PM, Cardoso AL, Custodia C, et al. MiRNA-21 silencing mediated by tumor-targeted nanoparticles combined with sunitinib: a new multimodal gene therapy approach for glioblastoma. J Control Release 2015;207:31-39.

103. Clinical Trial [Available from: https://www.clinicaltrials.gov/ct2/ show/NCT02340156?term $=$ NCT02340156\&rank $=1$. Accessed 27 Dec 2018.

104. Clinial Trial [Available from: https://www.clinicaltrials.gov/ct2/ show/NCT03020017?term $=$ NCT03020017\&rank=1. Accessed 27 Dec 2018

105. Jensen SA, Day ES, Ko CH, et al. Spherical nucleic acid nanoparticle conjugates as an RNAi-based therapy for glioblastoma. Sci Transl Med 2013;5:209ra152.

106. Choi CH, Hao L, Narayan SP, Auyeung E, Mirkin CA. Mechanism for the endocytosis of spherical nucleic acid nanoparticle conjugates. Proc Natl Acad Sci U S A 2013;110:7625-7630.

107. Wei Z, Batagov AO, Schinelli S, et al. Coding and noncoding landscape of extracellular RNA released by human glioma stem cells. Nat Commun 2017;8:1145.

108. Haraszti RA, Coles A, Aronin N, Khvorova A, Didiot MC. Loading of extracellular vesicles with chemically stabilized hydrophobic siRNAs for the treatment of disease in the central nervous system. Bio Protoc 2017;7:e2338. Available at: https://www. ncbi.nlm.nih.gov/pmc/articles/PMC5580947/. Accessed 27 Dec 2018.

109. Soria JC, Ohe Y, Vansteenkiste J, et al. Osimertinib in untreated EGFR-mutated advanced non-small-cell lung cancer. N Engl J Med 2018;378:113-125.

110. Bamias A, Escudier B, Sternberg CN, et al. Current clinical practice guidelines for the treatment of renal cell carcinoma: a systematic review and critical evaluation. Oncologist 2017;22:667-679.

111. Bredel M, Scholtens DM, Yadav AK, et al. NFKBIA deletion in glioblastomas. N Engl J Med 2011;364:627-637.

112. Rimkus TK, Carpenter RL, Sirkisoon S, et al. Truncated gliomaassociated oncogene homolog 1 (tGLI1) mediates mesenchymal glioblastoma via transcriptional activation of CD44. Cancer Res 2018;78:2589-2600.

113. Wang R, Degirmenci V, Xin H, et al. PEI-coated Fe(3)O(4) nanoparticles enable efficient delivery of therapeutic siRNA targeting REST into glioblastoma cells. Int J Mol Sci 2018;19:2230

114. Chen YT, Tsai HP, Wu CC, et al. High-level Sp1 is associated with proliferation, invasion, and poor prognosis in astrocytoma. Pathol Oncol Res 2018. https://doi.org/10.1007/s12253-018-0422-8. Accessed December 27, 2018.

115. Koessinger D, Albrecht V, Faber F, Jaehnert I, Schichor C. ETS-1 expression is hypoxia-independent in glioblastoma-derived endothelial and mesenchymal stem-like cells. Anticancer Res 2018;38: $3347-3355$.

116. Ganguly D, Fan M, Yang CH, et al. The critical role that STAT3 plays in glioma-initiating cells: STAT3 addiction in glioma. Oncotarget 2018;9:22095-22112.

117. Mikheev AM, Mikheeva SA, Severs LJ, et al. Targeting TWIST1 through loss of function inhibits tumorigenicity of human glioblastoma. Mol Oncol 2018;12:1188-1202.

118. Lee JV, Berry CT, Kim K, et al. Acetyl-CoA promotes glioblastoma cell adhesion and migration through $\mathrm{Ca}(2+)$-NFAT signaling. Genes Dev 2018;32:497-511.

119. Fazi B, Garbo S, Toschi N, et al. The lncRNA H19 positively affects the tumorigenic properties of glioblastoma cells and contributes to NKD1 repression through the recruitment of EZH2 on its promoter. Oncotarget 2018;9:15512-15525.

120. Jin X, Kim LJY, Wu Q, et al. Targeting glioma stem cells through combined BMI1 and EZH2 inhibition. Nat Med 2017;23:1352-1361.
121. Mai WX, Gosa L, Daniels VW, et al. Cytoplasmic p53 couples oncogene-driven glucose metabolism to apoptosis and is a therapeutic target in glioblastoma. Nat Med 2017;23:1342-1351.

122. Wang J, Cheng P, Pavlyukov MS, et al. Targeting NEK2 attenuates glioblastoma growth and radioresistance by destabilizing histone methyltransferase EZH2. J Clin Invest 2017;127:3075-3089.

123. Miller TE, Liau BB, Wallace LC, et al. Transcription elongation factors represent in vivo cancer dependencies in glioblastoma. Nature 2017;547:355-359.

124. Huang JL, Jiang G, Song QX, et al. Lipoprotein-biomimetic nanostructure enables efficient targeting delivery of siRNA to Rasactivated glioblastoma cells via macropinocytosis. Nat Commun 2017;8:15144

125. Rosmaninho P, Mukusch S, Piscopo V, et al. Zeb1 potentiates genome-wide gene transcription with Lef1 to promote glioblastoma cell invasion. EMBO J 2018;37:e97115. Available at: http:// emboj.embopress.org/content/37/15/e97115.long. Accessed 27 Dec 2018.

126. Liu Z, Wei Y, Zhang L, et al. Induction of store-operated calcium entry (SOCE) suppresses glioblastoma growth by inhibiting the Hippo pathway transcriptional coactivators YAP/TAZ. Oncogene 2019;38:120-139.

127. Yu OM, Benitez JA, Plouffe SW, et al. YAP and MRTF-A, transcriptional co-activators of RhoA-mediated gene expression, are critical for glioblastoma tumorigenicity. Oncogene 2018;37:5492-5507

128. Li S, Zhang W, Wu C, et al. HOXC10 promotes proliferation and invasion and induces immunosuppressive gene expression in glioma. FEBS J 2018;285:2278-2291.

129. Masilamani AP, Ferrarese R, Kling E, et al. KLF6 depletion promotes NF-kappaB signaling in glioblastoma. Oncogene 2017;36: 3562-3575.

130. Schulz-Heddergott R, Moll UM. Gain-of-function (GOF) mutant p53 as actionable therapeutic target. Cancers (Basel) 2018;10:116.

131. Yue $\mathrm{X}, \mathrm{Zhao} \mathrm{Y}, \mathrm{Xu} \mathrm{Y}$, et al. Mutant $\mathrm{p} 53$ in cancer: accumulation, gain-of-function, and therapy. J Mol Biol 2017;429:1595-1606.

132. Duffy MJ, Synnott NC, Crown J. Mutant p53 as a target for cancer treatment. Eur J Cancer 2017;83:258-265.

133. Puchalski RB, Shah N, Miller J, et al. An anatomic transcriptional atlas of human glioblastoma. Science 2018;360:660-663.

134. Osuka S, Van Meir EG. Overcoming therapeutic resistance in glioblastoma: the way forward. J Clin Invest 2017;127:415-426.

135. Lathia JD, Mack SC, Mulkearns-Hubert EE, Valentim CL, Rich JN. Cancer stem cells in glioblastoma. Genes Dev 2015;29:1203-1217.

136. Patel AP, Tirosh I, Trombetta JJ, et al. Single-cell RNA-seq highlights intratumoral heterogeneity in primary glioblastoma. Science 2014;344:1396-1401.

137. Osswald M, Jung E, Sahm F, et al. Brain tumour cells interconnect to a functional and resistant network. Nature 2015;528:93-98.

138. Gronych J, Pfister SM, Jones DT. Connect four with glioblastoma stem cell factors. Cell 2014;157:525-527.

139. Jun HJ, Appleman VA, Wu HJ, et al. A PDGFRalpha-driven mouse model of glioblastoma reveals a stathmin 1-mediated mechanism of sensitivity to vinblastine. Nat Commun 2018;9:3116.

140. Marie SK, Oba-Shinjo SM, da Silva R, et al. Stathmin involvement in the maternal embryonic leucine zipper kinase pathway in glioblastoma. Proteome Sci 2016;14:6.

141. Hu B, Wang Q, Wang YA, et al. Epigenetic activation of WNT5A drives glioblastoma stem cell differentiation and invasive growth. Cell 2016;167:1281-1295 e1218.

142. Alt EU, Barabadi Z, Pfnur A, et al. TRAF3IP2, a novel therapeutic target in glioblastoma multiforme. Oncotarget 2018;9:2977229788.

143. Barberi T, Martin A, Suresh R, et al. Absence of host NF-kappaB p50 induces murine glioblastoma tumor regression, increases survival, and decreases T-cell induction of tumor-associated 
macrophage M2 polarization. Cancer Immunol Immunother 2018;67:1491-1503.

144. Xiao B, Fan Y, Ye M, et al. Downregulation of COUP-TFII inhibits glioblastoma growth via targeting MPC1. Oncol Lett 2018;15:9697-9702.

145. Bowman T, Garcia R, Turkson J, Jove R. STATs in oncogenesis. Oncogene 2000;19:2474-2488.

146. Priester M, Copanaki E, Vafaizadeh V, et al. STAT3 silencing inhibits glioma single cell infiltration and tumor growth. Neuro Oncol 2013;15:840-852.

147. Zhang Z, Zheng X, Luan Y, et al. Activity of metabotropic glutamate receptor 4 suppresses proliferation and promotes apoptosis with inhibition of Gli-1 in human glioblastoma cells. Front Neurosci 2018;12:320.

148. Bazzoli E, Pulvirenti T, Oberstadt MC, et al. MEF promotes stemness in the pathogenesis of gliomas. Cell Stem Cell 2012;11:836-844.

149. Braun CJ, Stanciu M, Boutz PL, et al. Coordinated splicing of regulatory detained introns within oncogenic transcripts creates an exploitable vulnerability in malignant glioma. Cancer Cell 2017;32:411-426 e411.

150. Banasavadi-Siddegowda YK, Russell L, Frair E, et al. PRMT5PTEN molecular pathway regulates senescence and self-renewal of primary glioblastoma neurosphere cells. Oncogene 2017;36: 263-274.

151. Bageritz J, Puccio L, Piro RM, et al. Stem cell characteristics in glioblastoma are maintained by the ecto-nucleotidase E-NPP1. Cell Death Differ 2014;21:929-940.

152. Wang F, Wang AY, Chesnelong C, et al. ING5 activity in selfrenewal of glioblastoma stem cells via calcium and follicle stimulating hormone pathways. Oncogene 2018;37:286-301.

153. Cui Q, Yang S, Ye P, et al. Downregulation of TLX induces TET3 expression and inhibits glioblastoma stem cell self-renewal and tumorigenesis. Nat Commun 2016;7:10637.

154. Lin N, Di C, Bortoff K, et al. Deletion or epigenetic silencing of AJAP1 on 1p36 in glioblastoma. Mol Cancer Res 2012;10:208-217.

155. Bogeas A, Morvan-Dubois G, El-Habr EA, et al. Changes in chromatin state reveal ARNT2 at a node of a tumorigenic transcription factor signature driving glioblastoma cell aggressiveness. Acta Neuropathol 2018;135:267-283.

156. Quail DF, Bowman RL, Akkari L, et al. The tumor microenvironment underlies acquired resistance to CSF-1R inhibition in gliomas. Science 2016;352:aad3018.

157. Pyonteck SM, Akkari L, Schuhmacher AJ, et al. CSF-1R inhibition alters macrophage polarization and blocks glioma progression. Nat Med 2013;19:1264-1272.

158. Yan D, Kowal J, Akkari L, et al. Inhibition of colony stimulating factor-1 receptor abrogates microenvironment-mediated therapeutic resistance in gliomas. Oncogene 2017;36:6049-6058.

159. Barrow AD, Edeling MA, Trifonov V, et al. Natural killer cells control tumor growth by sensing a growth factor. Cell 2018;172: 534-548 e519.

160. Liu T, Ma W, Xu H, et al. PDGF-mediated mesenchymal transformation renders endothelial resistance to anti-VEGF treatment in glioblastoma. Nat Commun 2018;9:3439.

161. Hodgson JG, Yeh RF, Ray A, et al. Comparative analyses of gene copy number and mRNA expression in glioblastoma multiforme tumors and xenografts. Neuro Oncol 2009;11:477-487.

162. Soudah T, Mogilevsky M, Karni R, Yavin E. CLIP6-PNA-peptide conjugates: non-endosomal delivery of splice switching oligonucleotides. Bioconjug Chem 2017;28:3036-3042.

163. Li Z, Li Q, Han L, et al. Pro-apoptotic effects of splice-switching oligonucleotides targeting Bcl-x pre-mRNA in human glioma cell lines. Oncol Rep 2016;35:1013-1019.
164. Aldave G, Gonzalez-Huarriz M, Rubio A, et al. The aberrant splicing of BAF45d links splicing regulation and transcription in glioblastoma. Neuro Oncol 2018;20:930-941.

165. Brennan C, Momota H, Hambardzumyan D, et al. Glioblastoma subclasses can be defined by activity among signal transduction pathways and associated genomic alterations. PLoS One 2009;4:e7752.

166. Zorzan M, Giordan E, Redaelli M, Caretta A, Mucignat-Caretta C. Molecular targets in glioblastoma. Future Oncol 2015;11:1407-1420.

167. An Z, Aksoy O, Zheng T, Fan QW, Weiss WA. Epidermal growth factor receptor and EGFRvIII in glioblastoma: signaling pathways and targeted therapies. Oncogene 2018;37:1561-1575.

168. Zanca C, Villa GR, Benitez JA, et al. Glioblastoma cellular crosstalk converges on NF-kappaB to attenuate EGFR inhibitor sensitivity. Genes Dev 2017;31:1212-1227.

169. Nathanson DA, Gini B, Mottahedeh J, et al. Targeted therapy resistance mediated by dynamic regulation of extrachromosomal mutant EGFR DNA. Science 2014;343:72-76.

170. Chou ST, Patil R, Galstyan A, et al. Simultaneous blockade of interacting CK2 and EGFR pathways by tumor-targeting nanobioconjugates increases therapeutic efficacy against glioblastoma multiforme. J Control Release 2016;244:14-23.

171. Chen X, Zhang M, Gan H, et al. A novel enhancer regulates MGMT expression and promotes temozolomide resistance in glioblastoma. Nat Commun 2018;9:2949.

172. Ambady P, Wu YJ, Walker JM, et al. Enhancing the cytotoxicity of chemoradiation with radiation-guided delivery of anti-MGMT morpholino oligonucleotides in non-methylated solid tumors. Cancer Gene Ther 2017;24:348-357.

173. Zhu ZC, Liu JW, Li K, Zheng J, Xiong ZQ. KPNB1 inhibition disrupts proteostasis and triggers unfolded protein responsemediated apoptosis in glioblastoma cells. Oncogene 2018;37: 2936-2952.

174. Venkatesh HS, Johung TB, Caretti V, et al. Neuronal activity promotes glioma growth through neuroligin-3 secretion. Cell 2015;161:803-816.

175. Dolma S, Selvadurai HJ, Lan X, et al. Inhibition of dopamine receptor D4 impedes autophagic flux, proliferation, and survival of glioblastoma stem cells. Cancer Cell 2016;29:859-873.

176. Yuan M, Eberhart CG, Kai M. RNA binding protein RBM14 promotes radio-resistance in glioblastoma by regulating DNA repair and cell differentiation. Oncotarget 2014;5:2820-2826.

177. Marcelino Meliso F, Hubert CG, Favoretto Galante PA, Penalva LO. RNA processing as an alternative route to attack glioblastoma. Hum Genet 2017;136:1129-1141.

178. Ferrarese R, Harsh GRt, Yadav AK, et al. Lineage-specific splicing of a brain-enriched alternative exon promotes glioblastoma progression. J Clin Invest 2014;124:2861-2876.

179. Lefave CV, Squatrito M, Vorlova S, et al. Splicing factor hnRNPH drives an oncogenic splicing switch in gliomas. EMBO J 2011;30: $4084-4097$.

180. Kudinov AE, Karanicolas J, Golemis EA, Boumber Y. Musashi RNA-binding proteins as cancer drivers and novel therapeutic targets. Clin Cancer Res 2017;23:2143-2153.

181. Uren PJ, Vo DT, de Araujo PR, et al. RNA-binding protein Musashil is a central regulator of adhesion pathways in glioblastoma. Mol Cell Biol 2015;35:2965-2978.

182. Shao J, Zhang J, Zhang Z, et al. Alternative polyadenylation in glioblastoma multiforme and changes in predicted RNA binding protein profiles. OMICS 2013;17:136-149.

183. Correa BR, de Araujo PR, Qiao M, et al. Functional genomics analyses of RNA-binding proteins reveal the splicing regulator SNRPB as an oncogenic candidate in glioblastoma. Genome Biol 2016;17:125.

184. Rokaeus N, Shen J, Eckhardt I, et al. PRIMA-1(MET)/APR-246 targets mutant forms of p53 family members p63 and p73. Oncogene 2010;29:6442-6451. 
185. Guo G, Gong K, Ali S, et al. A TNF-JNK-Axl-ERK signaling axis mediates primary resistance to EGFR inhibition in glioblastoma. Nat Neurosci 2017;20:1074-1084.

186. He S, Cen B, Liao L, et al. A tumor-targeting cRGD-EGFR siRNA conjugate and its anti-tumor effect on glioblastoma in vitro and in vivo. Drug Deliv 2017;24:471-481.

187. Xie J, Ma YH, Wan M, Zhan RY, Zhou YQ. Expression of dedifferentiation markers and multilineage markers in U251 glioblastoma cells with silenced EGFR and FGFR genes. Oncol Lett 2014;7: 131-136.

188. Bell RJ, Rube HT, Kreig A, et al. Cancer. The transcription factor GABP selectively binds and activates the mutant TERT promoter in cancer. Science 2015;348:1036-1039.

189. George J, Banik NL, Ray SK. Knockdown of hTERT and concurrent treatment with interferon-gamma inhibited proliferation and invasion of human glioblastoma cell lines. Int J Biochem Cell Biol 2010;42:1164-1173.

190. Kohsaka S, Wang L, Yachi K, et al. STAT3 inhibition overcomes temozolomide resistance in glioblastoma by downregulating MGMT expression. Mol Cancer Ther 2012;11:1289-1299.

191. Carro MS, Lim WK, Alvarez MJ, et al. The transcriptional network for mesenchymal transformation of brain tumours. Nature 2010;463:318-325.

192. Zhou A, Lin K, Zhang S, et al. Gli1-induced deubiquitinase USP48 aids glioblastoma tumorigenesis by stabilizing Gli1. EMBO Rep 2017;18:1318-1330.

193. Zhu TS, Costello MA, Talsma CE, et al. Endothelial cells create a stem cell niche in glioblastoma by providing NOTCH ligands that nurture self-renewal of cancer stem-like cells. Cancer Res 2011;71:6061-6072.

194. Wang J, Wang C, Meng Q, et al. siRNA targeting Notch-1 decreases glioma stem cell proliferation and tumor growth. Mol Biol Rep 2012;39:2497-2503.

195. Mongiardi MP, Savino M, Falchetti ML, et al. c-MYC inhibition impairs hypoxia response in glioblastoma multiforme. Oncotarget 2016;7:33257-33271.

196. Kozono D, Li J, Nitta M, et al. Dynamic epigenetic regulation of glioblastoma tumorigenicity through LSD1 modulation of MYC expression. Proc Natl Acad Sci U S A 2015;112:E4055-4064.

197. Annibali D, Whitfield JR, Favuzzi E, et al. Myc inhibition is effective against glioma and reveals a role for Myc in proficient mitosis. Nat Commun 2014;5:4632.

198. Huang T, Alvarez AA, Pangeni RP, et al. A regulatory circuit of $\mathrm{miR}-125 \mathrm{~b} / \mathrm{miR}-20 \mathrm{~b}$ and Wnt signalling controls glioblastoma phenotypes through FZD6-modulated pathways. Nat Commun 2016;7:12885.

199. Yue X, Lan F, Yang W, et al. Interruption of beta-catenin suppresses the EGFR pathway by blocking multiple oncogenic targets in human glioma cells. Brain Res 2010;1366:27-37.

200. Pu P, Zhang Z, Kang C, et al. Downregulation of Wnt2 and betacatenin by siRNA suppresses malignant glioma cell growth. Cancer Gene Ther 2009;16:351-361.

201. Paul-Samojedny M, Pudelko A, Kowalczyk M, et al. Knockdown of AKT3 and PI3KCA by RNA interference changes the expression of the genes that are related to apoptosis and autophagy in T98G glioblastoma multiforme cells. Pharmacol Rep 2015;67: $1115-1123$

202. Ghosh MK, Sharma P, Harbor PC, Rahaman SO, Haque SJ. PI3KAKT pathway negatively controls EGFR-dependent DNA-binding activity of Stat 3 in glioblastoma multiforme cells. Oncogene 2005;24:7290-7300.

203. Yu Z, Chen Y, Wang S, et al. Inhibition of NF-kappaB results in anti-glioma activity and reduces temozolomide-induced chemoresistance by down-regulating MGMT gene expression. Cancer Lett 2018;428:77-89.
204. Yu D, Khan OF, Suva ML, et al. Multiplexed RNAi therapy against brain tumor-initiating cells via lipopolymeric nanoparticle infusion delays glioblastoma progression. Proc Natl Acad Sci U S A 2017;114:E6147-E6156.

205. Galardi S, Savino M, Scagnoli F, et al. Resetting cancer stem cell regulatory nodes upon MYC inhibition. EMBO Rep 2016;17: $1872-1889$.

206. Suva ML, Rheinbay E, Gillespie SM, et al. Reconstructing and reprogramming the tumor-propagating potential of glioblastoma stem-like cells. Cell 2014;157:580-594.

207. Bedikian AY, Garbe C, Conry R, et al. Dacarbazine with or without oblimersen (a Bcl-2 antisense oligonucleotide) in chemotherapy-naive patients with advanced melanoma and lownormal serum lactate dehydrogenase: 'The AGENDA trial'. Melanoma Res 2014;24:237-243.

208. O'Brien S, Moore JO, Boyd TE, et al. 5-Year survival in patients with relapsed or refractory chronic lymphocytic leukemia in a randomized, phase III trial of fludarabine plus cyclophosphamide with or without oblimersen. J Clin Oncol 2009;27:5208-5212.

209. Chanan-Khan AA, Niesvizky R, Hohl RJ, et al. Phase III randomised study of dexamethasone with or without oblimersen sodium for patients with advanced multiple myeloma. Leuk Lymphoma 2009;50:559-565.

210. Beer TM, Hotte SJ, Saad F, et al. Custirsen (OGX-011) combined with cabazitaxel and prednisone versus cabazitaxel and prednisone alone in patients with metastatic castration-resistant prostate cancer previously treated with docetaxel (AFFINITY): a randomised, open-label, international, phase 3 trial. Lancet Oncol 2017;18:1532-1542.

211. Chi KN, Higano CS, Blumenstein B, et al. Custirsen in combination with docetaxel and prednisone for patients with metastatic castration-resistant prostate cancer (SYNERGY trial): a phase 3, multicentre, open-label, randomised trial. Lancet Oncol 2017;18: 473-485.

212. Yu EY, Ellard SL, Hotte SJ, et al. A randomized phase 2 study of a HSP27 targeting antisense, apatorsen with prednisone versus prednisone alone, in patients with metastatic castration resistant prostate cancer. Invest New Drugs 2018;36:278-287.

213. Rosenberg JE, Hahn NM, Regan MM, et al. Apatorsen plus docetaxel versus docetaxel alone in platinum-resistant metastatic urothelial carcinoma (Borealis-2). Br J Cancer 2018;118:1434-1441.

214. Bellmunt J, Eigl BJ, Senkus E, et al. Borealis-1: a randomized, first-line, placebo-controlled, phase II study evaluating apatorsen and chemotherapy for patients with advanced urothelial cancer. Ann Oncol 2017;28:2481-2488.

215. Ko AH, Murphy PB, Peyton JD, et al. A randomized, doubleblinded, phase II trial of gemcitabine and nab-paclitaxel plus apatorsen or placebo in patients with metastatic pancreatic cancer: the RAINIER trial. Oncologist 2017;22:1427-e1129.

216. Ruzsa A, Sen M, Evans M, et al. Phase 2, open-label, 1:1 randomized controlled trial exploring the efficacy of EMD 1201081 in combination with cetuximab in second-line cetuximab-naive patients with recurrent or metastatic squamous cell carcinoma of the head and neck (R/M SCCHN). Invest New Drugs 2014;32:1278-1284.

217. Lee FA, Zee BC, Cheung FY, et al. Randomized phase II study of the X-linked inhibitor of apoptosis (XIAP) antisense AEG35156 in combination with sorafenib in patients with advanced hepatocellular carcinoma (HCC). Am J Clin Oncol 2016;39:609-613.

218. Schimmer AD, Herr W, Hanel M, et al. Addition of AEG35156 XIAP antisense oligonucleotide in reinduction chemotherapy does not improve remission rates in patients with primary refractory acute myeloid leukemia in a randomized phase II study. Clin Lymphoma Myeloma Leuk 2011;11:433-438.

219. Tolcher AW, Rodrigueza WV, Rasco DW, et al. A phase 1 study of the BCL2-targeted deoxyribonucleic acid inhibitor (DNAi) 
PNT2258 in patients with advanced solid tumors. Cancer Chemother Pharmacol 2014;73:363-371.

220. Dritschilo A, Huang CH, Rudin CM, et al. Phase I study of liposome-encapsulated c-raf antisense oligodeoxyribonucleotide infusion in combination with radiation therapy in patients with advanced malignancies. Clin Cancer Res 2006;12:1251-1259.

221. Duffy AG, Makarova-Rusher OV, Ulahannan SV, et al. Modulation of tumor eIF4E by antisense inhibition: a phase I/II translational clinical trial of ISIS 183750-an antisense oligonucleotide against eIF4E-in combination with irinotecan in solid tumors and irinotecan-refractory colorectal cancer. Int J Cancer 2016;139:1648-1657.

222. Rupaimoole R, Slack FJ. MicroRNA therapeutics: towards a new era for the management of cancer and other diseases. Nat Rev Drug Discov 2017;16:203-222.

223. Iorio MV, Croce CM. MicroRNA dysregulation in cancer: diagnostics, monitoring and therapeutics. A comprehensive review. EMBO Mol Med 2012;4:143-159.

224. Anfossi S, Babayan A, Pantel K, Calin GA. Clinical utility of circulating non-coding RNAs - an update. Nat Rev Clin Oncol 2018;15:541-563.

225. Visani M, de Biase D, Marucci G, et al. Expression of 19 microRNAs in glioblastoma and comparison with other brain neoplasia of grades I-III. Mol Oncol 2014;8:417-430.

226. Teplyuk NM, Mollenhauer B, Gabriely G, et al. MicroRNAs in cerebrospinal fluid identify glioblastoma and metastatic brain cancers and reflect disease activity. Neuro Oncol 2012;14:689-700.

227. Zhang Y, Cruickshanks N, Pahuski M, et al. Noncoding RNAs in glioblastoma. Chapter 6 in: De Vleeschouwer S, editor. Glioblastoma. Brisbane (AU) 2017. Available at: https:// codonpublications.com/index.php/codon/catalog/view/35/143/ 291-1. Accessed 27 Dec 2018.

228. Svoronos AA, Engelman DM, Slack FJ. OncomiR or tumor suppressor? The duplicity of microRNAs in cancer. Cancer Res 2016;76:3666-3670.

229. Teplyuk NM, Uhlmann EJ, Wong AH, et al. MicroRNA-10b inhibition reduces E2F1-mediated transcription and miR-15/16 activity in glioblastoma. Oncotarget 2015;6:3770-3783.

230. Gabriely G, Teplyuk NM, Krichevsky AM. Context effect: microRNA-10b in cancer cell proliferation, spread and death. Autophagy 2011;7:1384-1386.

231. Olive V, Li Q, He L. mir-17-92: a polycistronic oncomir with pleiotropic functions. Immunol Rev 2013;253:158-166.

232. Ernst A, Campos B, Meier J, et al. De-repression of CTGF via the miR-17-92 cluster upon differentiation of human glioblastoma spheroid cultures. Oncogene 2010;29:3411-3422.

233. Yuan GQ, Wei NL, Mu LY, et al. A 4-miRNAs signature predicts survival in glioblastoma multiforme patients. Cancer Biomark 2017;20:443-452.

234. Mogilyansky E, Rigoutsos I. The miR-17/92 cluster: a comprehensive update on its genomics, genetics, functions and increasingly important and numerous roles in health and disease. Cell Death Differ 2013;20:1603-1614.

235. Beg MS, Brenner AJ, Sachdev J, et al. Phase I study of MRX34, a liposomal miR-34a mimic, administered twice weekly in patients with advanced solid tumors. Invest New Drugs 2017;35:180-188.

236. Kim J, Zhang Y, Skalski M, et al. microRNA-148a is a prognostic oncomiR that targets MIG6 and BIM to regulate EGFR and apoptosis in glioblastoma. Cancer Res 2014;74:1541-1553.

237. Kim H, Huang W, Jiang X, et al. Integrative genome analysis reveals an oncomir/oncogene cluster regulating glioblastoma survivorship. Proc Natl Acad Sci U S A 2010;107:2183-2188.

238. Titze-de-Almeida R, David C, Titze-de-Almeida SS. The race of 10 synthetic RNAi-based drugs to the pharmaceutical market. Pharm Res 2017;34:1339-1363.
239. Chan JA, Krichevsky AM, Kosik KS. MicroRNA-21 is an antiapoptotic factor in human glioblastoma cells. Cancer Res 2005;65:6029-6033.

240. Javanmardi S, Aghamaali MR, Abolmaali SS, Mohammadi S, Tamaddon AM. miR-21, an oncogenic target miRNA for cancer therapy: molecular mechanisms and recent advancements in chemo and radio-resistance. Curr Gene Ther 2017;16:375-389.

241. Krichevsky AM, Gabriely G. miR-21: a small multi-faceted RNA. J Cell Mol Med 2009;13:39-53.

242. Gabriely G, Wurdinger T, Kesari S, et al. MicroRNA 21 promotes glioma invasion by targeting matrix metalloproteinase regulators. Mol Cell Biol 2008;28:5369-5380.

243. Yang CH, Yue J, Pfeffer SR, et al. MicroRNA-21 promotes glioblastoma tumorigenesis by down-regulating insulin-like growth factor-binding protein-3 (IGFBP3). J Biol Chem 2014;289: 25079-25087.

244. Kwak HJ, Kim YJ, Chun KR, et al. Downregulation of Spry2 by miR-21 triggers malignancy in human gliomas. Oncogene 2011;30:2433-2442.

245. Xiong Q, Zhong Q, Zhang J, et al. Identification of novel miR-21 target proteins in multiple myeloma cells by quantitative proteomics. J Proteome Res 2012;11:2078-2090.

246. Zhou X, Ren Y, Moore L, et al. Downregulation of miR-21 inhibits EGFR pathway and suppresses the growth of human glioblastoma cells independent of PTEN status. Lab Invest 2010;90: 144-155.

247. Gaur AB, Holbeck SL, Colburn NH, Israel MA. Downregulation of Pdcd 4 by mir-21 facilitates glioblastoma proliferation in vivo. Neuro Oncol 2011;13:580-590.

248. Sheedy FJ. Turning 21: induction of miR-21 as a key switch in the inflammatory response. Front Immunol 2015;6:19.

249. Costa PM, Cardoso AL, Mendonca LS, et al. Tumor-targeted chlorotoxin-coupled nanoparticles for nucleic acid delivery to glioblastoma cells: a promising system for glioblastoma treatment. Mol Ther Nucleic Acids 2013;2:e100.

250. Oh B, Song H, Lee D, et al. Anti-cancer effect of R3V6 peptidemediated delivery of an anti-microRNA-21 antisenseoligodeoxynucleotide in a glioblastoma animal model. J Drug Target 2017;25:132-139.

251. Shi Z, Zhang J, Qian X, et al. AC1MMYR2, an inhibitor of dicermediated biogenesis of Oncomir miR-21, reverses epithelialmesenchymal transition and suppresses tumor growth and progression. Cancer Res 2013;73:5519-5531.

252. Lee TJ, Yoo JY, Shu D, et al. RNA nanoparticle-based targeted therapy for glioblastoma through inhibition of oncogenic miR-21. Mol Ther 2017;25:1544-1555.

253. Gabriely G, Yi M, Narayan RS, et al. Human glioma growth is controlled by microRNA-10b. Cancer Res 2011;71:3563-3572.

254. El Fatimy R, Subramanian S, Uhlmann EJ, Krichevsky AM. Genome editing reveals glioblastoma addiction to microRNA10b. Mol Ther 2017;25:368-378.

255. Ma C, Wei F, Xia H, et al. MicroRNA-10b mediates TGF-beta1regulated glioblastoma proliferation, migration and epithelialmesenchymal transition. Int J Oncol 2017;50:1739-1748.

256. Guessous F, Alvarado-Velez M, Marcinkiewicz L, et al. Oncogenic effects of miR-10b in glioblastoma stem cells. J Neurooncol 2013;112:153-163.

257. Lin J, Teo S, Lam DH, Jeyaseelan K, Wang S. MicroRNA-10b pleiotropically regulates invasion, angiogenicity and apoptosis of tumor cells resembling mesenchymal subtype of glioblastoma multiforme. Cell Death Dis 2012;3:e398.

258. Sasayama T, Nishihara M, Kondoh T, Hosoda K, Kohmura E. MicroRNA-10b is overexpressed in malignant glioma and associated with tumor invasive factors, $\mathrm{UPAR}$ and RhoC. Int J Cancer 2009;125:1407-1413. 
259. Sun L, Yan W, Wang Y, et al. MicroRNA-10b induces glioma cell invasion by modulating MMP-14 and uPAR expression via HOXD10. Brain Res 2011;1389:9-18.

260. Ananta JS, Paulmurugan R, Massoud TF. Tailored nanoparticle codelivery of antimiR-21 and antimiR-10b augments glioblastoma cell kill by temozolomide: toward a "personalized" antimicroRNA therapy. Mol Pharm 2016;13:3164-3175.

261. Zhang C, Zhang J, Hao J, et al. High level of miR-221/222 confers increased cell invasion and poor prognosis in glioma. J Transl Med 2012;10:119.

262. Ueda R, Kohanbash G, Sasaki K, et al. Dicer-regulated microRNAs 222 and 339 promote resistance of cancer cells to cytotoxic T-lymphocytes by down-regulation of ICAM-1. Proc Natl Acad Sci U S A 2009;106:10746-10751.

263. Brognara E, Fabbri E, Montagner G, et al. High levels of apoptosis are induced in human glioma cell lines by co-administration of peptide nucleic acids targeting miR-221 and miR-222. Int $\mathrm{J}$ Oncol 2016;48:1029-1038.

264. Medina R, Zaidi SK, Liu CG, et al. MicroRNAs 221 and 222 bypass quiescence and compromise cell survival. Cancer Res 2008;68:2773-2780.

265. le Sage C, Nagel R, Egan DA, et al. Regulation of the p27(Kip1) tumor suppressor by miR-221 and miR-222 promotes cancer cell proliferation. EMBO J 2007;26:3699-3708.

266. Zhang CZ, Zhang JX, Zhang AL, et al. MiR-221 and miR-222 target PUMA to induce cell survival in glioblastoma. Mol Cancer 2010;9:229.

267. Quintavalle C, Garofalo M, Zanca C, et al. miR-221/222 overexpession in human glioblastoma increases invasiveness by targeting the protein phosphate PTPmu. Oncogene 2012;31:858-868.

268. Hao J, Zhang C, Zhang A, et al. miR-221/222 is the regulator of Cx43 expression in human glioblastoma cells. Oncol Rep 2012;27:1504-1510.

269. Fornari F, Pollutri D, Patrizi C, et al. In hepatocellular carcinoma miR221 modulates sorafenib resistance through inhibition of caspase-3mediated apoptosis. Clin Cancer Res 2017;23:3953-3965.

270. Gulla A, Di Martino MT, Gallo Cantafio ME, et al. A 13 mer LNA-i-miR-221 inhibitor restores drug sensitivity in melphalanrefractory multiple myeloma cells. Clin Cancer Res 2016;22: $1222-1233$.

271. Das SK, Sokhi UK, Bhutia SK, et al. Human polynucleotide phosphorylase selectively and preferentially degrades microRNA-221 in human melanoma cells. Proc Natl Acad Sci U S A 2010;107: 11948-11953.

272. Mercatelli N, Coppola V, Bonci D, et al. The inhibition of the highly expressed miR-221 and miR-222 impairs the growth of prostate carcinoma xenografts in mice. PLoS One 2008;3:e4029.

273. Skalsky RL, Cullen BR. Reduced expression of brain-enriched microRNAs in glioblastomas permits targeted regulation of a cell death gene. PLoS One 2011;6:e24248.

274. Silber J, Lim DA, Petritsch C, et al. miR-124 and miR-137 inhibit proliferation of glioblastoma multiforme cells and induce differentiation of brain tumor stem cells. BMC Med 2008;6:14.

275. Abernathy DG, Kim WK, McCoy MJ, et al. MicroRNAs induce a permissive chromatin environment that enables neuronal subtypespecific reprogramming of adult human fibroblasts. Cell Stem Cell 2017;21:332-348 e339.

276. Yoo AS, Staahl BT, Chen L, Crabtree GR. MicroRNA-mediated switching of chromatin-remodelling complexes in neural development. Nature 2009;460:642-646.

277. Makeyev EV, Zhang J, Carrasco MA, Maniatis T. The microRNA miR-124 promotes neuronal differentiation by triggering brainspecific alternative pre-mRNA splicing. Mol Cell 2007;27:435-448.

278. Krichevsky AM, Sonntag KC, Isacson O, Kosik KS. Specific microRNAs modulate embryonic stem cell-derived neurogenesis. Stem Cells 2006;24:857-864.
279. Ru Q, Li WL, Xiong Q, et al. Voltage-gated potassium channel blocker 4-aminopyridine induces glioma cell apoptosis by reducing expression of microRNA-10b-5p. Mol Biol Cell 2018;29: $1125-1136$.

280. Li Y, Zhao S, Zhen Y, et al. A miR-21 inhibitor enhances apoptosis and reduces $\mathrm{G}(2)-\mathrm{M}$ accumulation induced by ionizing radiation in human glioblastoma U251 cells. Brain Tumor Pathol 2011;28: 209-214.

281. Cui D, Sajan P, Shi J, et al. MiR-148a increases glioma cell migration and invasion by downregulating GADD45A in human gliomas with IDH1 R132H mutations. Oncotarget 2017;8: 25345-25361.

282. Wang H, Pan JQ, Luo L, et al. NF-kappaB induces miR-148a to sustain TGF-beta/Smad signaling activation in glioblastoma. Mol Cancer 2015;14:2.

283. Mucaj V, Lee SS, Skuli N, et al. MicroRNA-124 expression counteracts pro-survival stress responses in glioblastoma. Oncogene 2015;34:2204-2214.

284. Chen Q, Lu G, Cai Y, et al. MiR-124-5p inhibits the growth of high-grade gliomas through posttranscriptional regulation of LAMB1. Neuro Oncol 2014;16:637-651.

285. An L, Liu Y, Wu A, Guan Y. microRNA-124 inhibits migration and invasion by down-regulating ROCK1 in glioma. PLoS One 2013;8:e69478.

286. Deng X, Ma L, Wu M, et al. miR-124 radiosensitizes human glioma cells by targeting CDK4. J Neurooncol 2013;114:263-274.

287. Lang MF, Yang S, Zhao C, et al. Genome-wide profiling identified a set of miRNAs that are differentially expressed in glioblastoma stem cells and normal neural stem cells. PLoS One 2012;7: e36248.

288. Fowler A, Thomson D, Giles K, et al. miR-124a is frequently down-regulated in glioblastoma and is involved in migration and invasion. Eur J Cancer 2011;47:953-963.

289. Pierson J, Hostager B, Fan R, Vibhakar R. Regulation of cyclin dependent kinase 6 by microRNA 124 in medulloblastoma. J Neurooncol 2008;90:1-7.

290. Peruzzi P, Bronisz A, Nowicki MO, et al. MicroRNA-128 coordinately targets Polycomb Repressor Complexes in glioma stem cells. Neuro Oncol 2013;15:1212-1224.

291. Ambasudhan R, Talantova M, Coleman R, et al. Direct reprogramming of adult human fibroblasts to functional neurons under defined conditions. Cell Stem Cell 2011;9:113-118.

292. Wei J, Wang F, Kong LY, et al. miR-124 inhibits STAT3 signaling to enhance T cell-mediated immune clearance of glioma. Cancer Res 2013;73:3913-3926.

293. Lang FM, Hossain A, Gumin J, et al. Mesenchymal stem cells as natural biofactories for exosomes carrying miR-124a in the treatment of gliomas. Neuro Oncol 2018;20:380-390.

294. Yaghi NK, Wei J, Hashimoto Y, et al. Immune modulatory nanoparticle therapeutics for intracerebral glioma. Neuro Oncol 2017;19:372-382.

295. Sharif S, Ghahremani MH, Soleimani M. Delivery of exogenous miR-124 to glioblastoma multiform cells by Wharton's jelly mesenchymal stem cells decreases cell proliferation and migration, and confers chemosensitivity. Stem Cell Rev 2018;14:236-246.

296. Lee HK, Finniss S, Cazacu S, et al. Mesenchymal stem cells deliver synthetic microRNA mimics to glioma cells and glioma stem cells and inhibit their cell migration and self-renewal. Oncotarget 2013;4:346-361.

297. Godlewski J, Nowicki MO, Bronisz A, et al. Targeting of the Bmi-1 oncogene/stem cell renewal factor by microRNA-128 inhibits glioma proliferation and self-renewal. Cancer Res 2008;68:9125-9130.

298. Shi ZM, Wang J, Yan Z, et al. MiR-128 inhibits tumor growth and angiogenesis by targeting p70S6K1. PLoS One 2012;7:e32709. 
299. Mathew LK, Skuli N, Mucaj V, et al. miR-218 opposes a critical RTK-HIF pathway in mesenchymal glioblastoma. Proc Natl Acad Sci U S A 2014;111:291-296.

300. Xia H, Yan Y, Hu M, et al. MiR-218 sensitizes glioma cells to apoptosis and inhibits tumorigenicity by regulating ECOPmediated suppression of NF-kappaB activity. Neuro Oncol 2013;15:413-422.

301. Wu DG, Wang YY, Fan LG, et al. MicroRNA-7 regulates glioblastoma cell invasion via targeting focal adhesion kinase expression. Chin Med J (Engl) 2011;124:2616-2621.

302. Kefas B, Godlewski J, Comeau L, et al. microRNA-7 inhibits the epidermal growth factor receptor and the Akt pathway and is down-regulated in glioblastoma. Cancer Res 2008;68:3566-3572.

303. Babae N, Bourajjaj M, Liu Y, et al. Systemic miRNA-7 delivery inhibits tumor angiogenesis and growth in murine xenograft glioblastoma. Oncotarget 2014;5:6687-6700.

304. Zhang X, Zhang X, Hu S, et al. Identification of miRNA-7 by genome-wide analysis as a critical sensitizer for TRAIL-induced apoptosis in glioblastoma cells. Nucleic Acids Res 2017;45:5930-5944.

305. Zhang W, Zhang J, Hoadley K, et al. miR-181d: a predictive glioblastoma biomarker that downregulates MGMT expression. Neuro Oncol 2012;14:712-719.

306. Wang XF, Shi ZM, Wang XR, et al. MiR-181d acts as a tumor suppressor in glioma by targeting K-ras and Bcl-2. J Cancer Res Clin Oncol 2012;138:573-584.

307. Chen Y, Li R, Pan M, et al. MiR-181b modulates chemosensitivity of glioblastoma multiforme cells to temozolomide by targeting the epidermal growth factor receptor. J Neurooncol 2017;133:477-485.

308. Ma J, Yao Y, Wang P, et al. MiR-181a regulates blood-tumor barrier permeability by targeting Kruppel-like factor 6 . J Cereb Blood Flow Metab 2014;34:1826-1836.

309. Moskwa P, Zinn PO, Choi YE, et al. A functional screen identifies miRs that induce radioresistance in glioblastomas. Mol Cancer Res 2014;12:1767-1778.

310. Kouri FM, Ritner C, Stegh AH. miRNA-182 and the regulation of the glioblastoma phenotype - toward miRNA-based precision therapeutics. Cell Cycle 2015;14:3794-3800.

311. Kouri FM, Hurley LA, Daniel WL, et al. miR-182 integrates apoptosis, growth, and differentiation programs in glioblastoma. Genes Dev 2015;29:732-745.

312. Bai AH, Milde T, Remke M, et al. MicroRNA-182 promotes leptomeningeal spread of non-sonic hedgehog-medulloblastoma. Acta Neuropathol 2012;123:529-538.

313. Huynh C, Segura MF, Gaziel-Sovran A, et al. Efficient in vivo microRNA targeting of liver metastasis. Oncogene 2011;30:1481-1488.

314. Segura MF, Hanniford D, Menendez S, et al. Aberrant miR-182 expression promotes melanoma metastasis by repressing FOXO3 and microphthalmia-associated transcription factor. Proc Natl Acad Sci U S A 2009;106:1814-1819.

315. Xue J, Zhou A, Wu Y, et al. miR-182-5p induced by STAT3 activation promotes glioma tumorigenesis. Cancer Res 2016;76: 4293-4304.

316. Song $\mathrm{L}$, Liu $\mathrm{L}, \mathrm{Wu} \mathrm{Z}$, et al. TGF-beta induces miR-182 to sustain NF-kappaB activation in glioma subsets. J Clin Invest 2012;122: 3563-3578.

317. Derrien T, Johnson R, Bussotti G, et al. The GENCODE v7 catalog of human long noncoding RNAs: analysis of their gene structure, evolution, and expression. Genome Res 2012;22:1775-1789.

318. Briggs JA, Wolvetang EJ, Mattick JS, Rinn JL, Barry G. Mechanisms of long non-coding RNAs in mammalian nervous system development, plasticity, disease, and evolution. Neuron 2015;88:861-877.

319. Cabili MN, Dunagin MC, McClanahan PD, et al. Localization and abundance analysis of human lncRNAs at single-cell and singlemolecule resolution. Genome Biol 2015;16:20.
320. Zhou T, Kim Y, MacLeod AR. Targeting long noncoding RNA with antisense oligonucleotide technology as cancer therapeutics. Methods Mol Biol 2016;1402:199-213.

321. Meng L, Ward AJ, Chun S, et al. Towards a therapy for Angelman syndrome by targeting a long non-coding RNA. Nature 2015;518: 409-412.

322. Sarma K, Levasseur P, Aristarkhov A, Lee JT. Locked nucleic acids (LNAs) reveal sequence requirements and kinetics of Xist RNA localization to the X chromosome. Proc Natl Acad Sci U S A 2010;107:22196-22201.

323. Ozes AR, Wang Y, Zong X, et al. Therapeutic targeting using tumor specific peptides inhibits long non-coding RNA HOTAIR activity in ovarian and breast cancer. Sci Rep 2017;7:894.

324. Sprangers AJ, Hao L, Banga RJ, Mirkin CA. Liposomal spherical nucleic acids for regulating long noncoding RNAs in the nucleus. Small 2017;13:1-21.

325. Gagnon KT, Corey DR. Argonaute and the nuclear RNAs: new pathways for RNA-mediated control of gene expression. Nucleic Acid Ther 2012;22:3-16.

326. Stojic L, Niemczyk M, Orjalo A, et al. Transcriptional silencing of long noncoding RNA GNG12-AS1 uncouples its transcriptional and product-related functions. Nat Commun 2016;7:10406.

327. Cabili MN, Trapnell C, Goff L, et al. Integrative annotation of human large intergenic noncoding RNAs reveals global properties and specific subclasses. Genes Dev 2011;25:1915-1927.

328. Kelley D, Rinn J. Transposable elements reveal a stem cellspecific class of long noncoding RNAs. Genome Biol 2012;13: R107.

329. Peng Z, Liu C, Wu M. New insights into long noncoding RNAs and their roles in glioma. Mol Cancer 2018;17:61.

330. Reon BJ, Anaya J, Zhang Y, et al. Expression of lncRNAs in lowgrade gliomas and glioblastoma multiforme: an in silico analysis. PLoS Med 2016;13:e1002192.

331. Ma X, Li Z, Li T, et al. Long non-coding RNA HOTAIR enhances angiogenesis by induction of VEGFA expression in glioma cells and transmission to endothelial cells via glioma cell derivedextracellular vesicles. Am J Transl Res 2017;9:5012-5021.

332. Pastori C, Kapranov P, Penas C, et al. The Bromodomain protein BRD4 controls HOTAIR, a long noncoding RNA essential for glioblastoma proliferation. Proc Natl Acad Sci U S A 2015;112: 8326-8331.

333. Zhang K, Sun X, Zhou X, et al. Long non-coding RNA HOTAIR promotes glioblastoma cell cycle progression in an EZH2 dependent manner. Oncotarget 2015;6:537-546.

334. Zhou X, Ren Y, Zhang J, et al. HOTAIR is a therapeutic target in glioblastoma. Oncotarget 2015;6:8353-8365.

335. Sun G, Wang Y, Zhang J, Lin N, You Y. MiR-15b/HOTAIR/p53 form a regulatory loop that affects the growth of glioma cells. J Cell Biochem 2018;119:4540-4547.

336. Liu L, Cui S, Wan T, et al. Long non-coding RNA HOTAIR acts as a competing endogenous RNA to promote glioma progression by sponging miR-126-5p. J Cell Physiol 2018;233:6822-6831.

337. Ke J, Yao YL, Zheng J, et al. Knockdown of long non-coding RNA HOTAIR inhibits malignant biological behaviors of human glioma cells via modulation of miR-326. Oncotarget 2015;6: 21934-21949.

338. Matouk IJ, Mezan S, Mizrahi A, et al. The oncofetal H19 RNA connection: hypoxia, p53 and cancer. Biochim Biophys Acta 2010;1803:443-451.

339. Barsyte-Lovejoy D, Lau SK, Boutros PC, et al. The c-Myc oncogene directly induces the H19 noncoding RNA by allele-specific binding to potentiate tumorigenesis. Cancer Res 2006;66:5330-5337.

340. Chen L, Wang Y, He J, et al. Long non-coding RNA H19 promotes proliferation and invasion in human glioma cells by downregulating miR-152. Oncol Res 2018. https://doi.org/10.3727/ $096504018 X 15178768577951$. 
341. Jia L, Tian Y, Chen Y, Zhang G. The silencing of LncRNA-H19 decreases chemoresistance of human glioma cells to temozolomide by suppressing epithelial-mesenchymal transition via the Wnt/beta-Catenin pathway. Onco Targets Ther 2018;11:313-321.

342. Jia P, Cai H, Liu X, et al. Long non-coding RNA H19 regulates glioma angiogenesis and the biological behavior of gliomaassociated endothelial cells by inhibiting microRNA-29a. Cancer Lett 2016:381:359-369.

343. Jiang P, Wang P, Sun X, et al. Knockdown of long noncoding RNA H19 sensitizes human glioma cells to temozolomide therapy. Onco Targets Ther 2016;9:3501-3509.

344. Jiang X, Yan Y, Hu M, et al. Increased level of H19 long noncoding RNA promotes invasion, angiogenesis, and stemness of glioblastoma cells. J Neurosurg 2016;2016:129-136.

345. Zhang X, Sun S, Pu JK, et al. Long non-coding RNA expression profiles predict clinical phenotypes in glioma. Neurobiol Dis 2012;48:1-8.

346. Zheng J, Liu X, Wang P, et al. CRNDE promotes malignant progression of glioma by attenuating miR-384/PIWIL4/STAT3 axis. Mol Ther 2016;24:1199-1215.

347. Wang Y, Wang Y, Li J, et al. CRNDE, a long-noncoding RNA, promotes glioma cell growth and invasion through mTOR signaling. Cancer Lett 2015;367:122-128.

348. Katsushima K, Natsume A, Ohka F, et al. Targeting the Notchregulated non-coding RNA TUG1 for glioma treatment. Nat Commun 2016;7:13616.

349. Cai H, Liu X, Zheng J, et al. Long non-coding RNA taurine upregulated 1 enhances tumor-induced angiogenesis through inhibiting microRNA-299 in human glioblastoma. Oncogene 2017;36:318-331.

350. Zhou K, Zhang C, Yao H, et al. Knockdown of long non-coding RNA NEAT1 inhibits glioma cell migration and invasion via modulation of SOX2 targeted by miR-132. Mol Cancer 2018;17:105.

351. Chen Q, Cai J, Wang Q, et al. Long noncoding RNA NEAT1, regulated by the EGFR pathway, contributes to glioblastoma progression through the WNT/beta-catenin pathway by scaffolding EZH2. Clin Cancer Res 2018;24:684-695.

352. Cheng $\mathrm{Z}, \mathrm{Li} \mathrm{Z}$, Ma K, et al. Long non-coding RNA XIST promotes glioma tumorigenicity and angiogenesis by acting as a molecular sponge of miR-429. J Cancer 2017;8:4106-4116.

353. Yu H, Xue Y, Wang P, et al. Knockdown of long non-coding RNA XIST increases blood-tumor barrier permeability and inhibits glioma angiogenesis by targeting miR-137. Oncogenesis 2017;6: e303.

354. Zhang S, Zhao BS, Zhou A, et al. m(6)A demethylase ALKBH5 maintains tumorigenicity of glioblastoma stem-like cells by sustaining FOXM1 expression and cell proliferation program. Cancer Cell 2017;31:591-606 e596.

355. Guo H, Hu G, Yang Q, et al. Knockdown of long non-coding RNA CCAT2 suppressed proliferation and migration of glioma cells. Oncotarget 2016;7:81806-81814.

356. Wang ZH, Guo XQ, Zhang QS, et al. Long non-coding RNA CCAT1 promotes glioma cell proliferation via inhibiting microRNA-410. Biochem Biophys Res Commun 2016;480: 715-720.

357. Deguchi S, Katsushima K, Hatanaka A, et al. Oncogenic effects of evolutionarily conserved noncoding RNA ECONEXIN on gliomagenesis. Oncogene 2017;36:4629-4640.

358. Yang JX, Liu B, Yang BY, Meng Q. Long non-coding RNA homeobox (HOX) A11-AS promotes malignant progression of glioma by targeting miR-124-3p. Neoplasma 2018;65:505-514.

359. Wu F, Zhang C, Cai J, et al. Upregulation of long noncoding RNA HOXA-AS3 promotes tumor progression and predicts poor prognosis in glioma. Oncotarget 2017;8:53110-53123.

360. Han Y, Wu Z, Wu T, et al. Tumor-suppressive function of long noncoding RNA MALAT1 in glioma cells by downregulation of
MMP2 and inactivation of ERK/MAPK signaling. Cell Death Dis 2016;7:e2123.

361. Vassallo I, Zinn P, Lai M, et al. WIF1 re-expression in glioblastoma inhibits migration through attenuation of non-canonical WNT signaling by downregulating the IncRNA MALAT1. Oncogene 2016;35:12-21.

362. Zhao X, Wang P, Liu J, et al. Gas5 exerts tumor-suppressive functions in human glioma cells by targeting miR-222. Mol Ther 2015;23:1899-1911.

363. Wang P, Liu YH, Yao YL, et al. Long non-coding RNA CASC2 suppresses malignancy in human gliomas by miR-21. Cell Signal 2015;27:275-282.

364. Maude SL, Laetsch TW, Buechner J, et al. Tisagenlecleucel in children and young adults with B-cell lymphoblastic leukemia. N Engl J Med 2018;378:439-448.

365. Neelapu SS, Locke FL, Bartlett NL, et al. Axicabtagene ciloleucel CAR T-cell therapy in refractory large B-cell lymphoma. N Engl J Med 2017;377:2531-2544.

366. Janjigian YY, Bendell J, Calvo E, et al. CheckMate-032 Study: efficacy and safety of nivolumab and nivolumab plus ipilimumab in patients with metastatic esophagogastric cancer. J Clin Oncol 2018;36:2836-2844.

367. Hellmann MD, Ciuleanu TE, Pluzanski A, et al. Nivolumab plus ipilimumab in lung cancer with a high tumor mutational burden. $\mathrm{N}$ Engl J Med 2018;378:2093-2104.

368. Carlino MS, Long GV, Schadendorf D, et al. Outcomes by line of therapy and programmed death ligand 1 expression in patients with advanced melanoma treated with pembrolizumab or ipilimumab in KEYNOTE-006: a randomised clinical trial. Eur J Cancer 2018;101:236-243.

369. Motzer RJ, Tannir NM, McDermott DF, et al. Nivolumab plus ipilimumab versus sunitinib in advanced renal-cell carcinoma. N Engl J Med 2018;378:1277-1290.

370. Filley AC, Henriquez M, Dey M. Recurrent glioma clinical trial, CheckMate-143: the game is not over yet. Oncotarget 2017;8: 91779-91794.

371. Sahin A, Sanchez C, Bullain S, et al. Development of third generation anti-EGFRvIII chimeric T cells and EGFRvIII-expressing artificial antigen presenting cells for adoptive cell therapy for glioma. PLoS One 2018;13:e0199414.

372. Wang D, Aguilar B, Starr R, et al. Glioblastoma-targeted CD4+ CAR T cells mediate superior antitumor activity. JCI Insight 2018;3:e99048. https://doi.org/10.1172/jci.insight.99048.

373. Pituch KC, Miska J, Krenciute G, et al. Adoptive transfer of IL13Ralpha2-specific chimeric antigen receptor $\mathrm{T}$ cells creates a pro-inflammatory environment in glioblastoma. Mol Ther 2018;26:986-995.

374. Pellegatta S, Savoldo B, Di Ianni N, et al. Constitutive and TNFalpha-inducible expression of chondroitin sulfate proteoglycan 4 in glioblastoma and neurospheres: implications for CAR-T cell therapy. Sci Transl Med 2018;10:eaao2731

375. Zhu X, Prasad S, Gaedicke S, et al. Patient-derived glioblastoma stem cells are killed by CD133-specific CAR T cells but induce the T cell aging marker CD57. Oncotarget 2015;6:171-184.

376. Nellan A, Rota C, Majzner R, et al. Durable regression of medulloblastoma after regional and intravenous delivery of anti-HER2 chimeric antigen receptor T cells. J Immunother Cancer 2018;6:30.

377. Ohno M, Ohkuri T, Kosaka A, et al. Expression of miR-17-92 enhances anti-tumor activity of T-cells transduced with the antiEGFRvIII chimeric antigen receptor in mice bearing human GBM xenografts. J Immunother Cancer 2013;1:21.

378. Jung IY, Kim YY, Yu HS, et al. CRISPR/Cas9-mediated knockout of DGK improves antitumor activities of human T cells. Cancer Res 2018;78:4692-4703. 
379. Glas M, Coch C, Trageser D, et al. Targeting the cytosolic innate immune receptors RIG-I and MDA5 effectively counteracts cancer cell heterogeneity in glioblastoma. Stem Cells 2013;31:1064-1074.

380. Yoon S, Rossi JJ. Therapeutic potential of small activating RNAs (saRNAs) in human cancers. Curr Pharm Biotechnol 2018;19: 604-610

381. Kelley ML, Strezoska Z, He K, Vermeulen A, Smith A. Versatility of chemically synthesized guide RNAs for CRISPR-Cas9 genome editing. J Biotechnol 2016;233:74-83.

382. Ryan DE, Taussig D, Steinfeld I, et al. Improving CRISPR-Cas specificity with chemical modifications in single-guide RNAs. Nucleic Acids Res 2018;46:792-803.

383. Basila M, Kelley ML, Smith AVB. Minimal 2'-O-methyl phosphorothioate linkage modification pattern of synthetic guide RNAs for increased stability and efficient CRISPR-Cas9 gene editing avoiding cellular toxicity. PLoS One 2017;12:e0188593.

384. Yin H, Song CQ, Suresh S, et al. Structure-guided chemical modification of guide RNA enables potent non-viral in vivo genome editing. Nat Biotechnol 2017;35:1179-1187.

385. Mir A, Alterman JF, Hassler MR, et al. Heavily and fully modified RNAs guide efficient SpyCas9-mediated genome editing. Nat Commun 2018;9:2641.
386. Finn JD, Smith AR, Patel MC, et al. A single administration of CRISPR/Cas9 lipid nanoparticles achieves robust and persistent in vivo genome editing. Cell Rep 2018;22:2227-2235.

387. Zhang Y, Chao T, Li R, et al. MicroRNA-128 inhibits glioma cells proliferation by targeting transcription factor E2F3a. J Mol Med (Berl) 2009;87:43-51

388. Liu Y, Yan W, Zhang W, et al. MiR-218 reverses high invasiveness of glioblastoma cells by targeting the oncogenic transcription factor LEF1. Oncol Rep 2012;28:1013-1021.

389. Tamim S, Vo DT, Uren PJ, et al. Genomic analyses reveal broad impact of miR-137 on genes associated with malignant transformation and neuronal differentiation in glioblastoma cells. PLoS One 2014;9:e85591.

390. Bier A, Giladi N, Kronfeld N, et al. MicroRNA-137 is downregulated in glioblastoma and inhibits the stemness of glioma stem cells by targeting RTVP-1. Oncotarget 2013;4:665-676.

391. Chen L, Wang X, Wang H, et al. miR-137 is frequently downregulated in glioblastoma and is a negative regulator of Cox-2. Eur J Cancer 2012;48:3104-3111. 